\title{
Synthesis, Characterization, and Photocatalytic Activity of Pure and N-, B-, or Ag- Doped $\mathrm{TiO}_{2}$
}

\author{
Paula C. S. Bezerra, ${ }^{a}$ Rodrigo P. Cavalcante, ${ }^{a}$ Aline Garcia,${ }^{b}$ Heberton Wender, ${ }^{c}$ \\ Marco A. U. Martines, ${ }^{a}$ Gleison A. Casagrande, ${ }^{a}$ Jaime Giménez, ${ }^{d}$ Pilar Marco, ${ }^{d}$ \\ Silvio C. Oliveira ${ }^{a}$ and Amilcar Machulek $\mathbf{J r} . * a, b$
}

a'Instituto de Química, Universidade Federal de Mato Grosso do Sul,
Av. Senador Filinto Müller, 1555, 79074-460 Campo Grande-MS, Brazil

${ }^{b}$ Faculdade de Engenharias, Arquitetura e Urbanismo e Geografia and Instituto de Física, Universidade Federal de Mato Grosso do Sul, Cidade Universitária, Av. Costa e Silva, s/n, 79070-900 Campo Grande-MS, Brazil

${ }^{d}$ Department of Chemical Engineering, Universitat de Barcelona, Martí i Franquès, 1, 08028 Barcelona, Spain

\begin{abstract}
This article reports the synthesis and characterization of pure and N-, B-, and Ag-doped $\mathrm{TiO}_{2}$ and the ability of these oxides to photodegrade methylene blue (MB) under sunlight or UV-ABC radiation. The compounds were synthesized using the sol-gel method and characterized by scanning electron microscopy, X-ray diffraction, diffuse reflectance spectroscopy, Fourier transform infrared spectroscopy, thermogravimetric analysis, and X-ray photoelectron spectroscopy. Photocatalytic efficiency was significantly increased by $\mathrm{N}$-doping, resulting in $98 \% \mathrm{MB}$ decomposition under UV-ABC irradiation for $180 \mathrm{~min}$. $\mathrm{Ag}$ - and $\mathrm{B}$-doped $\mathrm{TiO}_{2}$ lowered $\mathrm{MB}$ degradation rates to 52 and $73 \%$, respectively, compared with pure $\mathrm{TiO}_{2}$. The same behavior was observed with exposure to UV-Vis, with 88, 65, 60, and 42\% MB removal with N-doped, pure, B-doped, and Ag-doped $\mathrm{TiO}_{2}$, respectively. Under visible light alone, $\mathrm{N}$-doped $\mathrm{TiO}_{2}$ exhibited higher photocatalytic efficiency than commercial P25-type $\mathrm{TiO}_{2}$. Photocatalysis with $\mathrm{N}$-doped $\mathrm{TiO}_{2}$ proved to be a promising alternative for $\mathrm{MB}$ degradation, given the potential of employing solar energy, thus minimizing operating costs.
\end{abstract} activity

Keywords: photocatalyst, sol-gel method, $\mathrm{N}$-doped $\mathrm{TiO}_{2}$, UV-ABC irradiation, visible-light

\section{Introduction}

Incomplete removal of organic compounds in conventional wastewater treatment plants (WWTPs) has been identified as one of the principal routes whereby anthropogenic pollutants can reach aqueous environments. ${ }^{1}$ Use of advanced oxidation processes (AOPs), however, has proved a satisfactory approach to the treatment of wastewater containing biorecalcitrant organic pollutants. ${ }^{2,3}$

AOPs are based on physical and chemical mechanisms that produce powerful oxidizing species, primarily, but not limited to, hydroxyl radicals (HO'), generated under atmospheric or sub-supercritical conditions of temperature

*e-mail: machulekjr@gmail.com and pressure with the aid of catalysts, reactive energy (electrochemical, UV-Vis, ultrasound), both, or neither. ${ }^{4,5}$

The versatility of AOPs also stems from the availability of several routes for $\mathrm{HO}^{*}$ production, imparting high adaptability to environmental recovery approaches, ${ }^{2,6}$ including methods based on $\mathrm{UV}, \mathrm{H}_{2} \mathrm{O}_{2} / \mathrm{UV}, \mathrm{O}_{3} / \mathrm{UV}$, and $\mathrm{H}_{2} \mathrm{O}_{2} / \mathrm{O}_{3} / \mathrm{UV}$, which rely on UV-C photolysis of $\mathrm{H}_{2} \mathrm{O}_{2}$, ozone, or both to produce active species. UV-Vis irradiation is employed in methods such as photoFenton, in which $\mathrm{H}_{2} \mathrm{O}_{2}$ is added to dissolved iron salts and heterogeneous photocatalysis, while a powder or a supported semiconductor is used as the active material. ${ }^{2}$

In heterogeneous photocatalysis, which involves photoreaction acceleration in the presence of a semiconductor, irradiation with energy higher than bandgap $\left(300<\lambda<390 \mathrm{~nm}\right.$ for $\left.\mathrm{TiO}_{2}\right)$, generates valence 
band holes, $\left(h_{\mathrm{VB}}^{+}\right)$and conduction band electrons $\left(\mathrm{e}_{\mathrm{CB}}^{-}\right)$on the semiconductor surface (equation 1). ${ }^{2,4,7}$ Photoexcited electrons can in turn recombine with electron holes, reducing the overall efficiency of the photoprocess (equation 2). ${ }^{8}$ Unrecombined holes can subsequently oxidize organic pollutants through redox reactions (equation 3 ) or react with species adsorbed onto the catalyst surface, such as water or hydroxide ions $\left(\mathrm{HO}^{-}\right)$, to generate HO' radicals (equations 4 and 5). ${ }^{4,9}$ Electrons ejected to the conduction band can react with electron acceptors, such as molecular oxygen adsorbed onto the catalyst surface, forming superoxide anion radicals, $\mathrm{O}_{2}{ }^{--}$(equation 6), ${ }^{4}$ which react with protons to form hydroperoxyl radicals $\left(\mathrm{HO}_{2}{ }^{\circ}\right)$. Coupling of these radicals generates $\mathrm{H}_{2} \mathrm{O}_{2}$, which, undergoing photolysis, yield additional $\mathrm{HO}^{*}$ radicals. ${ }^{4}$

During photocatalysis, free electrons/holes and the reactive oxidizing species generated $\left(\mathrm{HO}^{*}, \mathrm{O}_{2}{ }^{--}, h_{\mathrm{VB}}^{+}, \mathrm{HO}_{2}{ }^{\circ}\right)$ are the principal species responsible for the degradation of organic pollutants present in the medium (equation 7). ${ }^{10}$

$$
\begin{aligned}
& \text { Semiconductor }+h v \rightarrow \mathrm{e}_{\mathrm{CB}}^{-}+h_{\mathrm{VB}}^{+} \\
& \mathrm{e}_{\mathrm{CB}}^{-}+h_{\mathrm{VB}}^{+} \rightarrow \text { energy } \\
& h_{\mathrm{VB}}^{+}+\mathrm{R} \rightarrow \mathrm{R}^{\cdot+} \\
& h_{\mathrm{VB}}^{+}+\mathrm{H}_{2} \mathrm{O}_{\mathrm{ads}} \rightarrow \mathrm{HO}_{\text {free }}^{\cdot}+\mathrm{H}^{+} \\
& h_{\mathrm{VB}}^{+}+\mathrm{HO}_{\text {ads }}^{-} \rightarrow \mathrm{HO}_{\text {ads }}^{-} \\
& \mathrm{e}_{\mathrm{CB}}^{-}+\mathrm{O}_{2} \rightarrow \mathrm{O}_{2}^{-} \\
& \mathrm{ROS}+\text { pollutant } \rightarrow \rightarrow \rightarrow \mathrm{HO}_{2}+\mathrm{CO}_{2}
\end{aligned}
$$

Titanium dioxide $\left(\mathrm{TiO}_{2}\right)$ is the most extensively used photocatalyst, owing to advantageous properties such as significant photocatalytic activity, operation under ambient conditions, thermal and chemical stability, low cost, low toxicity, abundance, and resistance to most chemicals and photocorrosion. ${ }^{10,11}$ Heterogeneous photocatalysis using $\mathrm{TiO}_{2}$ has received considerable attention as an AOP for photodegradation of organic pollutants in water. ${ }^{12-15}$

Despite being a promising technology, photocatalysis with $\mathrm{TiO}_{2}$ has disadvantages, including low degradation kinetics and a high probability of electron-hole recombination. Removal of catalysts at the end of the process is a major requirement in photocatalysis, albeit one difficult to meet, as it involves a solid-liquid separation step that adds to the overall capital and running costs in WWTPs. ${ }^{16,17}$ AOP application to full-scale water treatment is therefore under development. Combining catalysis with renewable energy resources, however, as in solar photocatalysis, is expected to cut down treatment costs and make AOPs more attractive to the water industry. ${ }^{18}$

An example of treatment of washing waters from pesticide containers is provided by a plant in Almería (Spain) that uses solar energy. ${ }^{19}$ Another is the
Mané Garrincha Stadium in Brasília (Brazil), renovated for the 2014 FIFA World Cup and often cited as a sustainable building for its self-cleaning roof consisting of a $\mathrm{TiO}_{2}$-coated polytetrafluoroethylene membrane. ${ }^{20}$

AOPs have proved advantageous even when complete degradation and mineralization of contaminants is not required, since doing so would not be cost-effective. Instead, the process can be aimed at partial degradation, to decrease the toxicity of organic pollutants, increase their biodegradability, or both, ${ }^{21}$ while letting byproducts of the reaction be degraded by microorganisms in a biological post-treatment step. ${ }^{22}$

Investigating the efficiency of $\mathrm{TiO}_{2}$ photocatalysis can provide a timely contribution to water treatment approaches, particularly in view of water scarcity at the global scale.

In semiconductors, photocatalytic efficiency depends mostly on the ability of the material to generate longerlived electrons and holes that can lead to generation of reactive species. ${ }^{10}$ Recombination of electron-hole pairs has been described as the chief factor limiting photocatalytic reactions.

A number of strategies to improve the photocatalytic activity of $\mathrm{TiO}_{2}$ by modifying its physical and chemical properties have been explored. These include increasing surface area, reducing particle size, generating structured mesoporous materials, creating a double-phase structure containing anatase and rutile, decreasing bandgap, and extending the light absorption range by incorporating metals or non-metals into a titania matrix. ${ }^{23,24}$ Since pure $\mathrm{TiO}_{2}$ absorbs virtually no visible light, or does so only slightly, incorporation of non-metals can extend absorption to the visible range. ${ }^{23}$ Doping with non-metals (such as N, $\mathrm{F}$, S, or B) or metals (among them $\mathrm{Ag}, \mathrm{Fe}, \mathrm{Pd}, \mathrm{Pt}, \mathrm{Rh}$, or $\mathrm{Ru}$ ) has improved the photocatalytic reactivity of $\mathrm{TiO}_{2} \cdot{ }^{25}$

Doping with noble metals such as $\mathrm{Ag}$ improves $\mathrm{TiO}_{2}$ photocatalytic activity by modifying its surface properties (e.g., surface area per mass, porosity) and extending the radiation absorption range to the visible spectrum. ${ }^{14,26}$ Doping $\mathrm{TiO}_{2}$ with non-metals, such as nitrogen and boron, has received special attention. ${ }^{20,27,28}$ The use of these anionic dopants leads to bandgap narrowing or formation of localized mid-bandgap states, effectively extending the absorption threshold of $\mathrm{TiO}_{2}$ into the visible range ${ }^{29} \mathrm{and} / \mathrm{or}$ causing physical and chemical changes in the particles, including increased surface area, formation of mesoporous structures, uniformity in particle surface size, formation of a double-phase structure of anatase and rutile, and decreased crystal and particle sizes. ${ }^{20}$

$\mathrm{N}$-doped $\mathrm{TiO}_{2}$ is the most widely investigated aniondoped form of this oxide, since nitrogen has structural 
properties similar to those of oxygen, the principal component of $\mathrm{TiO}_{2} \cdot{ }^{29}$ Furthermore, production of the compound is simple (a controllable synthesis process) and has low cost. ${ }^{27}$ On the basis of electronic band structure modification, the sufficient overlapping of $\mathrm{N} 2 \mathrm{p}$ states with O $2 p$ states at maximum valence band provides efficient bandgap narrowing for visible-light absorption. ${ }^{29} \mathrm{~S}$-doping can produce similar bandgap narrowing, yet sulfur, for its large ionic radius, is not easily incorporated into $\mathrm{O}$ sites in $\mathrm{TiO}_{2} .{ }^{29} \mathrm{C}$ - or P-doping, on the other hand, can introduce states too deep within the gap, which might serve as undesired recombination centers. ${ }^{29}$ Therefore, $\mathrm{N}-\mathrm{TiO}_{2}$ remains the leading visible-light-sensitive photocatalyst. However, Nishijima et al. ${ }^{30}$ have demonstrated that $\mathrm{S}$-doping renders $\mathrm{TiO}_{2}$ more efficient than its $\mathrm{N}$-doped counterpart as a photocatalyst under visible light for $\mathrm{H}_{2}$ evolution. Ivanov et al. ${ }^{31}$ reported that $\mathrm{S}$ - and C-codoped $\mathrm{TiO}_{2}$ showed excellent photocatalytic performance during degradation of organic dyes (rhodamine B, methylene blue), gas-phase oxidation of ethanol under visible light, and photocatalytic hydrogen generation from ethanol under UV radiation.

Wang et al. ${ }^{32}$ reported that doping $\mathrm{TiO}_{2}$ with boron promotes photogenerated electron-hole separation, improving photocatalytic efficiency. In experiments conducted by Liang et al., ${ }^{33} \mathrm{~B}$-doped $\mathrm{TiO}_{2}$ exhibited high photocatalytic efficiency, attributed to decreased bandgap energy, during rhodamine B degradation under simulated sunlight.

Zaleska et al. $^{34}$ reported that B-doping a $\mathrm{TiO}_{2}$ matrix using the sol-gel method facilitated transformation of the amorphous structure into anatase. Quiñones et al. ${ }^{35}$ demonstrated that the presence of boron reduced anatase crystal size in $\mathrm{TiO}_{2}$ particles and increased pore volume and surface area, relative to the pure oxide.

Cavalcante et al. ${ }^{12}$ demonstrated a substantial improvement in $\mathrm{TiO}_{2}$ photocatalytic efficiency by B-doping. Factors responsible for the improved performance included large surface area, mesoporous structure, anatase-rutile crystalline structure, formation of $\mathrm{Ti}^{\mathrm{III}}$, introduction of boron as a B-O-Ti species, uniformity in particle surface size, and decreased crystal and particle sizes.

Elghniji et al. ${ }^{36}$ synthesized $\mathrm{N}$-doped $\mathrm{TiO}_{2}$ nanoparticles using the sol-gel reverse micelle method and investigated their visible-light photocatalytic activity in methylene blue (MB) discoloration. Experimental results revealed that $\mathrm{N}$-doped $\mathrm{TiO}_{2}$ with a $\mathrm{N} / \mathrm{Ti}$ atomic ratio of 0.05 required shorter irradiation time for complete discoloration of $\mathrm{MB}$ than did pure nano- $\mathrm{TiO}_{2}$ or commercial $\mathrm{TiO}_{2} \mathrm{P}-25$ (Degussa). This remarkable photocatalytic efficiency was attributed to synergistic effects of nitrogen species, high specific surface area, and a pure anatase crystalline framework.

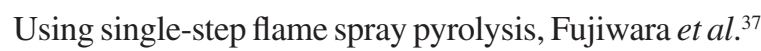
synthesized Ag-doped $\mathrm{TiO}_{2}$ particles that proved highly effective catalysts in MB degradation under visible light.

Although many advantages have been reported for the incorporation of various elements into titania matrices, few studies have compared the efficiency of the resulting catalysts with that of $\mathrm{TiO}_{2} \mathrm{P} 25$ powder, one of the most efficient commercial photocatalysts. This scarcity warrants comparing the photocatalytic efficiencies of commercial P25-type and laboratory-synthesized $\mathrm{TiO}_{2}$.

Metal doping can have disadvantages: doped materials exhibit low thermal stability, while metal leaching and possible toxicity diminish potential applicability to water treatment. Furthermore, metal centers can act as deep electron traps, reducing photocatalytic efficiency ${ }^{38}$ Further studies are thus necessary to ascertain optimal doping doses and their effect on $\mathrm{TiO}_{2}$ photocatalytic activity.

In this study, $\mathrm{X}$-doped $\mathrm{TiO}_{2}$ synthesis $(\mathrm{X}=\mathrm{N}, \mathrm{B}$, or $\mathrm{Ag}$ ) was examined as a strategy to increase the rate of $\mathrm{MB}$ photodegradation under irradiation with visible light. MB was selected as a pollutant model for its relative stability, which hampers its degradation by traditional wastewater treatment methods. Newly developed dyes are typically more resistant to photolysis, oxidation, and biodegradation than traditional counterparts. ${ }^{39} \mathrm{MB}$ is also the most common compound employed in cotton, wood, and silk dyeing. MB inhalation can lead to breathing problems; direct contact can cause eye damage, local burns, nausea, vomiting, hyperhidrosis, and mental disorders. ${ }^{40}$

In the present study, the oxides were characterized by thermogravimetric analysis (TGA), X-ray diffraction (XRD), scanning and transmission electron microscopy (SEM and TEM), specific surface area calculation using the Brunauer-Emmett-Teller (BET) method, Fourier transform infrared spectroscopy (FTIR), diffuse reflectance UV-Vis spectroscopy (DR-UV-Vis), and X-ray photoelectron spectroscopy (XPS).

\section{Experimental}

\section{Materials}

All reagents were of analytical grade. MB (82\%) and titanium(IV) isopropoxide (97\%) were purchased from Sigma-Aldrich. Isopropyl alcohol (99.8\%), silver nitrate (99.8\%, PA), and ammonia (25\%) were obtained from Merck. Nitric acid (65\% v/v) and glacial acetic acid (99.7\%) were acquired from Synth, boric acid from Dinâmica, and $\mathrm{TiO}_{2} \mathrm{P} 25$ from Evonik. Millipore Millex syringe-driven, 
$0.45 \mu \mathrm{m}$ pore size polyethersulfone membrane filters were employed. Deionized water was used in all experiments.

\section{Synthesis of catalysts}

Pure $\mathrm{TiO}_{2}$ and B-, $\mathrm{Ag}$-, and $\mathrm{N}$-modified $\mathrm{TiO}_{2}$ nanoparticles were synthesized from titanium(IV) isopropoxide using the sol-gel method, adapted from Cavalcante $\mathrm{et} \mathrm{al.}{ }^{12}$

A $19.10 \mathrm{~mL}$ volume of titanium(IV) isopropoxide was mixed with $16.10 \mathrm{~mL}$ of glacial acetic acid (molar ratio 1:4) under constant stirring until a metal acetate complex was formed. The acid acted as a chelant agent, controlling the hydrolysis process. After homogenization, $19.10 \mathrm{~mL}$ of isopropyl alcohol (Ti/alcohol ratio 1:1, v/v) were added and the solution was stirred for $1 \mathrm{~h}$, after which a solution consisting of $30 \mathrm{~mL}$ of water and $1 \mathrm{~mL}$ of nitric acid was added to the mixture, followed by another $2 \mathrm{~h}$ stirring while keeping the molar ratios of $\mathrm{H}_{2} \mathrm{O} / \mathrm{Ti}$ at 25 and $\mathrm{H}^{+} / \mathrm{Ti}$ at 0.5 . The system was subsequently maintained at $40{ }^{\circ} \mathrm{C}$ for around $48 \mathrm{~h}$. The resulting $\mathrm{TiO}_{2}$ solution was then dried in an oven at $100^{\circ} \mathrm{C}$ for $24 \mathrm{~h}$ and the powder thus obtained was macerated in a mortar and calcined at $450{ }^{\circ} \mathrm{C}$ for $4 \mathrm{~h}$.

Preparation of B-, N-, and Ag-doped $\mathrm{TiO}_{2}$ followed the same procedure, but employing $1.44 \mathrm{~g}$ of boric acid, $1.34 \mathrm{~mL}$ of ammonia, and $0.40 \mathrm{~g}$ of silver nitrate as the boron, nitrogen, and silver precursors, respectively. Each precursor was dissolved in a solution containing $30 \mathrm{~mL}$ of water and $1 \mathrm{~mL}$ of nitric acid. These amounts of dopants were calculated to yield catalysts at a $5 \%$ ratio $(\mathrm{m} / \mathrm{m})$, based on previous investigations by our research group. ${ }^{12,13}$

\section{Characterization}

Surface morphology was examined using a JSM7100F scanning electron microscope and a JEM-2100 transmission electron microscope (both Jeol). For SEM, the samples were mounted on carbon tape and sputter-coated with gold. For TEM, the samples were dispersed in ethanol with the aid of ultrasound and deposited onto copper grids. Particle diameter was determined using ImageJ software to count the particles seen in TEM images acquired from different fields in each sample. ${ }^{41}$

The crystal structures of powders were investigated by XRD from $8^{\circ}$ to $70^{\circ}(2 \theta)$ at $0.02^{\circ}$ increments with a measuring time of $5 \mathrm{~s}$ per step, employing a D2 Phaser diffractometer (Bruker) with a $\mathrm{CuK} \alpha$ radiation source $(\lambda=1.15418 \mathrm{~nm})$. Rietveld ${ }^{42}$ parameters were calculated using Von Dreele and Toby's General Structure Analysis System-II Crystal Structure Refinement package (GSAS-II) ${ }^{43}$ Thermogravimetric measurements were performed on a thermobalance, with samples placed in an alumina crucible and analyzed on a TGA Q50 device (Shimadzu) at a heating rate of $10{ }^{\circ} \mathrm{C} \mathrm{min}^{-1}$ and scan temperatures from 25 to $900{ }^{\circ} \mathrm{C}$, under a $\mathrm{N}_{2}$ flow rate of $50 \mathrm{~mL} \mathrm{~min}^{-1}$ in the furnace.

UV-Vis diffuse reflectance electronic spectra of the powders were obtained using a Lambda $650 \mathrm{UV}$-Vis spectrometer (PerkinElmer) equipped with an integrating sphere for diffuse reflectance. Scans were performed at 200 and $800 \mathrm{~nm}$. The UV-Vis spectra recorded in diffuse reflectance $\left(R_{\text {sample }}\right)$ mode were transformed using the Kubelka-Munk function, which is based on determination of Kubelka-Munk absorption $(K)$ and scattering $(S)$ coefficients, using equation $8: 44,45$

$F\left(R_{\infty}\right)=\frac{\left(1-R_{\infty}\right)^{2}}{2 R_{\infty}}=\frac{K}{S}$

where $R_{\infty}$ is defined as $R_{\text {sample }} / R_{\text {reference }}$, with $R_{\text {reference }}$ as the diffuse reflectance value obtained for $\mathrm{BaSO}_{4}$ using equation $9: 45$

$\left(F\left(R_{\infty}\right) h v\right)^{\frac{1}{m}}=C\left(h v-E_{\text {gap }}\right)$

where $C$ is a constant and $m$ is a constant that depends on the optical transition mode. Indirect optical bandgap values $\left(E_{\text {gap }} ; \mathrm{eV}\right)$ were obtained from a Tauc plot, $\left(F\left(R_{\infty}\right) h v\right)^{1 / 2}$, as a function of photon energy $h v$, considering the intersection of the linear portion of the curve with the $\mathrm{x}$-axis. ${ }^{45}$ For FTIR, the samples were shaped into pellets using potassium bromide and spectra recorded on a PerkinElmer 100 spectrophotometer in the $4000-450 \mathrm{~cm}^{-1}$ range. Elemental composition was determined by XPS. The experiments were performed in a K-Alpha spectrometer (Thermo Scientific) with a monochromatic X-ray source $(\mathrm{AlK} \alpha)$. The carbon contamination $\mathrm{C} 1 \mathrm{~s}$ peak appearing at $284.80 \mathrm{eV}$ was used as the reference for binding energy calibration. All acquired spectra were treated with CasaXPS software. Specific surface areas were determined via nitrogen adsorption analysis based on BET isotherms. Pore size distribution and total volume, based on BrunauerJoyner-Hallenda (BJH) isotherms, were determined on a TriStar 300 instrument (Micrometrics).

\section{Photodegradation assays}

Photocatalytic efficiency was evaluated by monitoring the degradation rate of $\mathrm{MB}$ under $\mathrm{UV}-\mathrm{ABC}$ radiation and simulated sunlight. In an annular glass photoreactor (working volume, $0.5 \mathrm{~L}$ ), a quartz tube was employed to insert the UV-ABC radiation source (Figure 1A), an 80 W HPL-N, high-pressure mercury vapor lamp (Orsan, 
222-578 nm, $254 \mathrm{~nm}$ maximum absorbance)..$^{46}$ Photon flux inside the photoreactor was $3.71 \times 10^{19}$ photons s$^{-1}$, experimentally determined by chemical actinometry with $0.15 \mathrm{~mol} \mathrm{~L}^{-1}$ potassium ferrioxalate complex. ${ }^{47} \mathrm{~A}$ magnetic stirrer homogenized the solution throughout the experiment. The jacket temperature $\left(25^{\circ} \mathrm{C}\right)$ of the stirred tank was controlled with the aid of a thermostatic bath. Photodegradation experiments employed a MB aqueous solution $\left(120 \mathrm{mg} \mathrm{L}^{-1}\right)$ containing $0.5 \mathrm{~g} \mathrm{~L}^{-1}$ of catalyst. The experiments were performed without $\mathrm{pH}$ control (pH ca. $5.0 \pm 0.2$ ). Reaction time was $180 \mathrm{~min}$ and aliquots were collected at predetermined intervals and filtered with Millipore Millex syringe-driven, $0.45 \mu \mathrm{m}$ pore-size polyethersulfone membrane filters to remove the catalyst before the analytical procedures. MB degradation was monitored by UV-Vis absorption, with measurements at $664 \mathrm{~nm}$ (the longest wavelength of MB) on a U-3000 UV-Vis spectrophotometer (Hitachi). To monitor MB concentration, a calibration curve was obtained, which obeyed Beer's law in the $0.25-4.0 \mathrm{mg} \mathrm{L}^{-1}$ range, with Abs (a.u.) $=0.00509+0.32156\left[\mathrm{MB}, \mathrm{mg} \mathrm{L}^{-1}\right], R=0.9971$, $S D=0.036$.

Artificial sunlight irradiation was performed with a solar simulator (Abet Technology; Figure 1B) equipped with a $150 \mathrm{~W}$ XOP xenon lamp (Abet Technology). For runs performed under visible light, a $400 \mathrm{~nm}$ cutoff filter was placed between lamp and reactor. The experiments were conducted in a borosilicate glass container positioned immediately below the lamp, at a height adjusted to collect the desired radiation, while the solution was continuously homogenized using a magnetic stirrer. Irradiation intensity was calibrated at $200 \mathrm{~mW} \mathrm{~cm} \mathrm{~cm}^{-2}$ using a 15151 reference cell (Abet Technologies) with direct incidence of photons on the liquid surface on top of the glass container. A $25 \mathrm{~mL}$ volume of solution containing $40 \mathrm{mg} \mathrm{L}^{-1}$ of $\mathrm{MB}$ and $12.5 \mathrm{mg}$ of catalyst was photoirradiated. Prior to irradiation, the solution was slurred with an appropriate amount of catalyst and allowed to equilibrate in the dark for $60 \mathrm{~min}$. The experiments were performed without $\mathrm{pH}$ control (pH ca. 5.0). Reaction time was $180 \mathrm{~min}$ and aliquots were collected at predetermined intervals. MB degradation was monitored by UV-Vis absorption.

\section{Results and Discussion}

\section{Characterization results}

The materials were morphologically characterized to evaluate the influence of $\mathrm{B}, \mathrm{N}$, and $\mathrm{Ag}$ incorporation into synthesized $\mathrm{TiO}_{2}$. SEM images of pure and $\mathrm{N}-$, B-, and Ag-doped $\mathrm{TiO}_{2}$ (Figure 2) revealed oxides constituted of

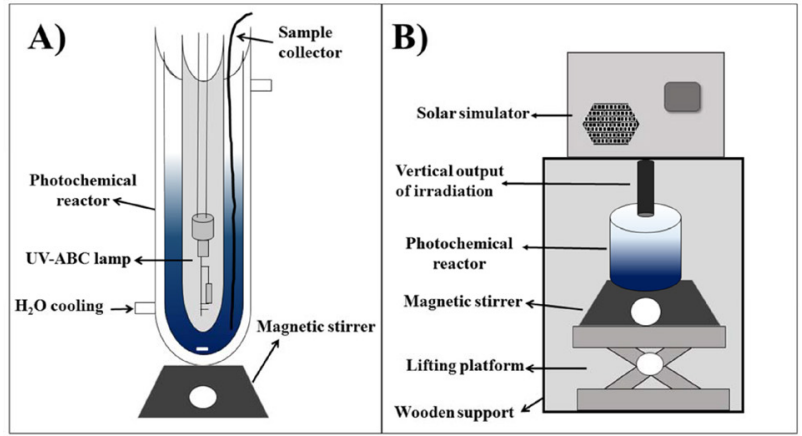

Figure 1. Schematic depiction of degradation systems: (A) photochemical reactor with UV-ABC lamp; (B) solar simulator and experimental instruments.

large aggregate particles, each in the nanometer range, although not individually discernible because of insufficient image resolution.

Representative TEM images and histograms of estimated particle size (Feret diameter) distribution for pure and $\mathrm{N}$-doped $\mathrm{TiO}_{2}$ are shown in Figure 3. $\mathrm{TiO}_{2}$ particles were polydisperse. Their dimensions could not be accurately determined, but most ranged from 5 to $30 \mathrm{~mm}$, in both samples.

The synthesized samples were subjected to TGA to evaluate stability or thermodecomposition (Figure 4). TGA curves for pure, $\mathrm{N}$-doped, and $\mathrm{Ag}$-doped $\mathrm{TiO}_{2}$ revealed a final weight loss (up to $900{ }^{\circ} \mathrm{C}$ ) of only $3-4 \%$. Weight loss was more pronounced between room temperature and ca. $100{ }^{\circ} \mathrm{C}$, a phenomenon attributed to evaporation of water adsorbed onto the catalyst surface. Weight loss in the 200-400 ${ }^{\circ} \mathrm{C}$ range possibly resulted from decomposition of organic solvents and organic matter, organic residues are often present in samples synthesized by the sol-gel method. Above $400{ }^{\circ} \mathrm{C}$, no major weight loss was observed, which demonstrates the stability and purity of the prepared catalysts.

As shown by the thermogravimetric curve for B-doped $\mathrm{TiO}_{2}$, mass loss was greater than for other samples up to ca. $300{ }^{\circ} \mathrm{C}$. In this range, roughly $10 \%$ of the original mass was lost, which can be attributed to thermal decomposition of residual organic groups in $\mathrm{B}$-doped $\mathrm{TiO}_{2}$. Boron may be incorporated into a $\mathrm{TiO}_{2}$ matrix as a Ti-O-B bond and/or transformed into a $\mathrm{B}_{2} \mathrm{O}_{3}$ phase. ${ }^{12,13}$ Having only three valence electrons, boron can behave as a Lewis acid, ${ }^{48}$ facilitating surface adsorption of water, with subsequent diffusion into the bulk of the material. This may explain the higher weight losses associated with water elimination from this catalyst up to $200{ }^{\circ} \mathrm{C}$.

Diffuse reflectance spectra of pure and doped $\mathrm{TiO}_{2}$ are shown in Figure 5A. For the doped samples, the typical absorption edge (due to electronic transitions from valence band to conduction band in $\mathrm{TiO}_{2}$ ) was modified by the onset of 

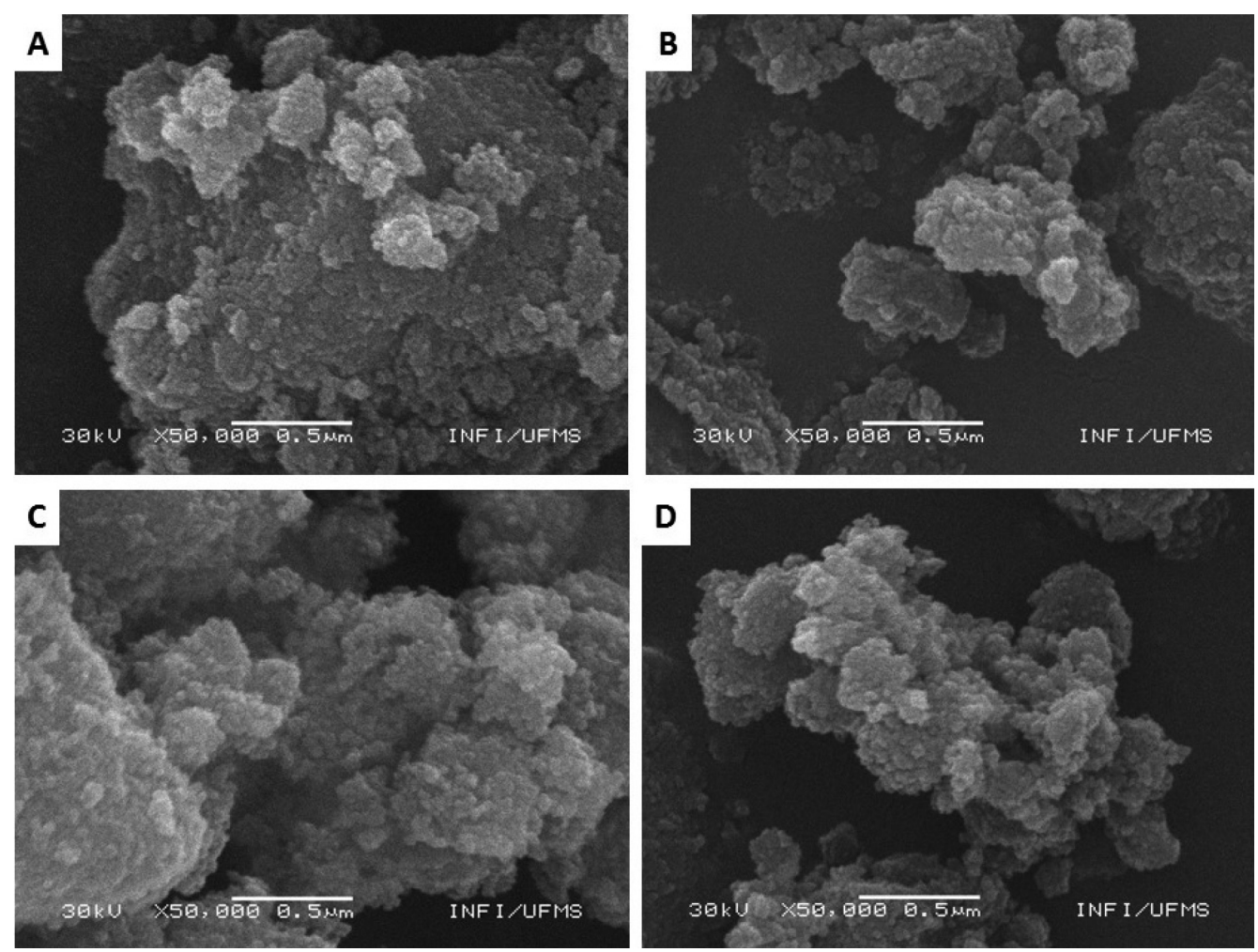

Figure 2. SEM images of (A) pure, (B) B-doped, (C) N-doped, and (D) Ag-doped $\mathrm{TiO}_{2}$.
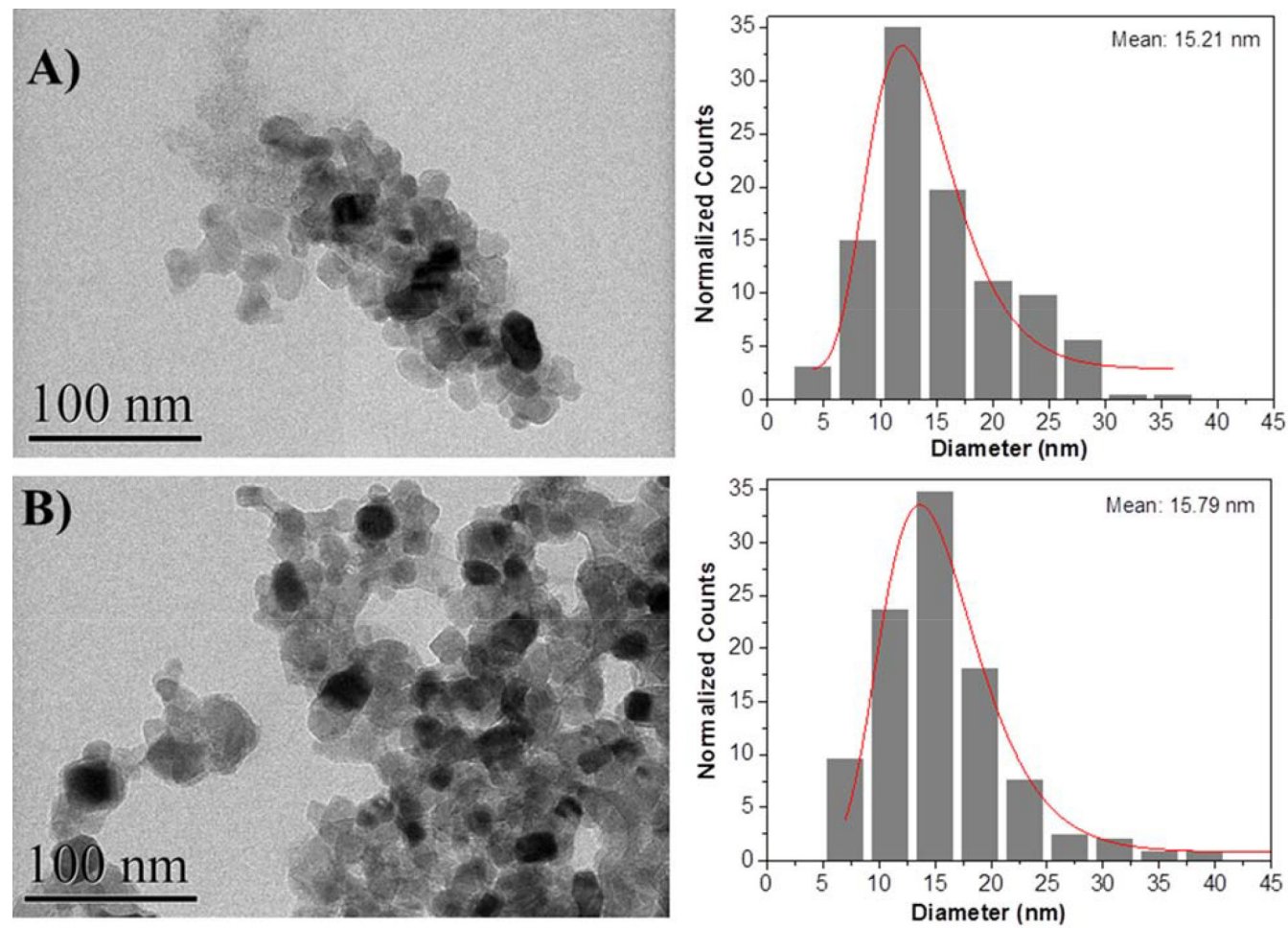

Figure 3. TEM images and particle distribution of (A) pure and (B) N-doped $\mathrm{TiO}_{2}$.

a relatively broad absorption band in the visible region, whose intensity depended on sample type ${ }^{49}$ This modification in the absorption edge was less pronounced for B- and N-doped samples, and more evident for Ag-doped $\mathrm{TiO}_{2}$. Extrapolation of tangent lines of Kubelka-Munk functions vs. photon energy provided $E_{\text {gap }}$ values for each oxide (Figure 5B). For all catalysts, the estimated $E_{\text {gap }}$ values remained within the 3.0-3.2 eV range (see values in Figure 5B), which is in 


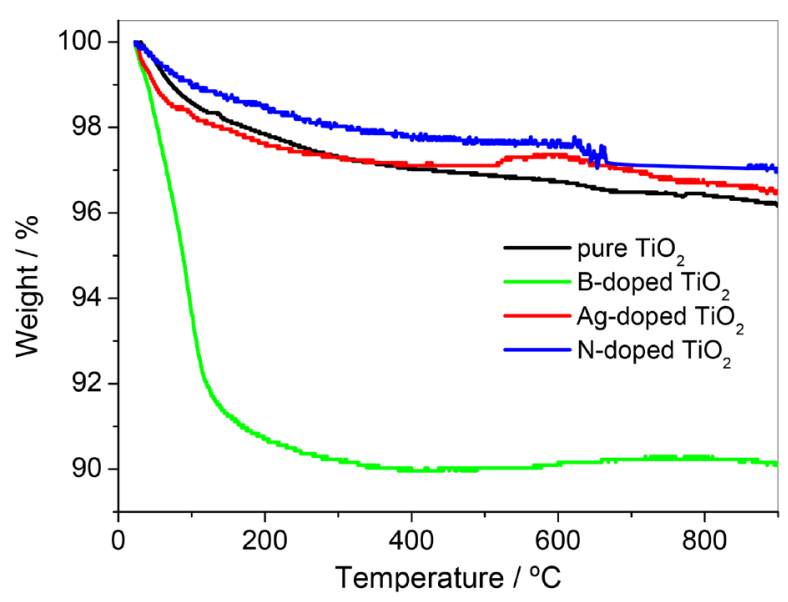

Figure 4. Thermogravimetric curves of synthesized photocatalysts.

agreement with other studies..$^{35} \mathrm{Ag}$-doped $\mathrm{TiO}_{2}$ exhibited lower $E_{\text {gap }}$ than the other catalysts investigated, which is consistent with a study by Ramos et al.,${ }^{14}$ who found $E_{\text {gap }}$ values to decrease with rising amounts of added silver. In our case, it should be noted that the absorption intensity of $\mathrm{Ag}$-doped $\mathrm{TiO}_{2}$ did not converge to zero beyond band edge, extending absorption into the visible range.

The infrared spectra of pure and doped $\mathrm{TiO}_{2}$ nanoparticles (Figure 6) showed broad bands in the $3000-3400 \mathrm{~cm}^{-1}$ range (with a maximum at $3200 \mathrm{~cm}^{-1}$ ) that probably represent $\mathrm{O}-\mathrm{H}$ stretching vibration from adsorbed water. A band in the $1610-1650 \mathrm{~cm}^{-1}$ range corresponded to the $\mathrm{OH}$ bending vibration mode of water adsorbed onto the oxide surface. ${ }^{50}$ After B-doping, the $\mathrm{O}-\mathrm{H}$ stretching vibration band became broader, possibly owing to the larger amount of water adsorbed onto the $\mathrm{TiO}_{2}$ surface. This is in accordance with TGA results.

Absorption bands were also found at $600 \mathrm{~cm}^{-1}$ and might be attributed to typical Ti-O-Ti vibration. ${ }^{51}$ After

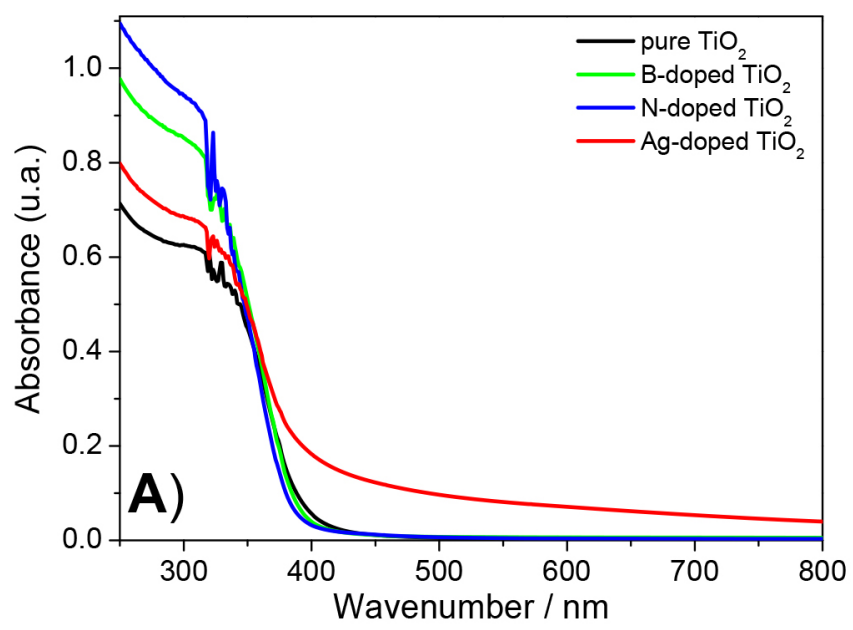

$\mathrm{N}$-doping, the Ti-O stretching vibration band became broader, possibly as a result of interaction with the doping nitrogen and the hydrogen from the hydroxyl group. ${ }^{50}$

In the FTIR spectrum of $\mathrm{B}-\mathrm{TiO}_{2}$ nanoparticles, the pronounced intensity observed in the $1300-1500 \mathrm{~cm}^{-1}$ region (with a maximum at $1400 \mathrm{~cm}^{-1}$ ) was ascribed to asymmetric B-O stretching on the surface. ${ }^{52}$ Boric acid species possibly ascribed to the presence of tricoordinated interstitial boron (in the form of B 3p), as well as outersphere boric acid, are potential sources of the peak seen around $1300-1400 \mathrm{~cm}^{-1} .32,52$ The band at $1200 \mathrm{~cm}^{-1}$, commonly attributed to stretching vibration of $\mathrm{B}-\mathrm{O}$ bonds, corroborates these findings. ${ }^{32,53}$

Phase compositions and crystal structures of pure and doped $\mathrm{TiO}_{2}$ were investigated by XRD (Figure 7). All diffraction peaks of the annealed powders were indexed to the anatase phase of $\mathrm{TiO}_{2}$, with characteristic occurrences at $25.4,37.8,48.1,54.2,55.2$, and $62.7^{\circ}, 1^{12,33}$ except for B-doped $\mathrm{TiO}_{2}$, where a peak characteristic of the rutile phase was observed at $27.8^{\circ},{ }^{12,33}$ indicating that boron may be incorporated into this phase, as observed earlier. ${ }^{13}$

Rietveld refinements were performed for a detailed examination of phase compositions and structural features of pure and $\mathrm{N}$-doped $\mathrm{TiO}_{2}$. For comparison, the procedure was also applied to commercial $\mathrm{TiO}_{2} \mathrm{P} 25$. Refined parameters that include crystallite size and unit-cell parameters were calculated (Table 1).

Anisotropic equatorial and axial crystal sizes were estimated at 13.3 and $14.4 \mathrm{~nm}$ for pure $\mathrm{TiO}_{2}$ and at 17.0 and $20.4 \mathrm{~nm}$ for $\mathrm{N}$-doped $\mathrm{TiO}_{2}$, respectively. The synthesized oxide is therefore constituted of smaller crystals than those of commercial $\mathrm{TiO}_{2}$. This confirms that both pure and $\mathrm{N}$-doped $\mathrm{TiO}_{2}$ crystallizes in the tetragonal pattern of anatase. Figure 8 shows the final Rietveld refinement plots.

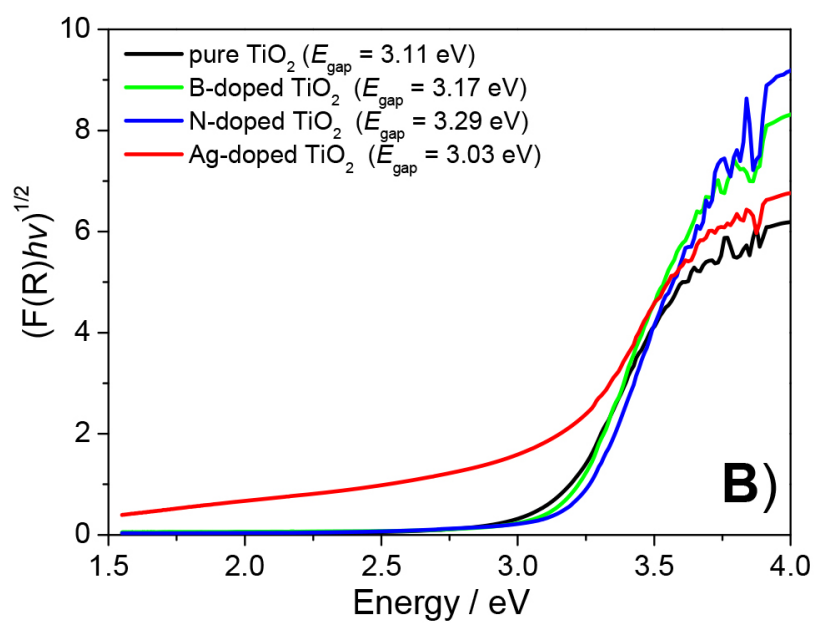

Figure 5. (A) UV-Vis absorption spectra and (B) Tauc plots of the square root of the Kubelka-Munk function $R_{\infty}\left(F\left(R_{\infty}\right) h v\right)^{1 / 2} v s$. photon energy for determining indirect bandgap energy values. 


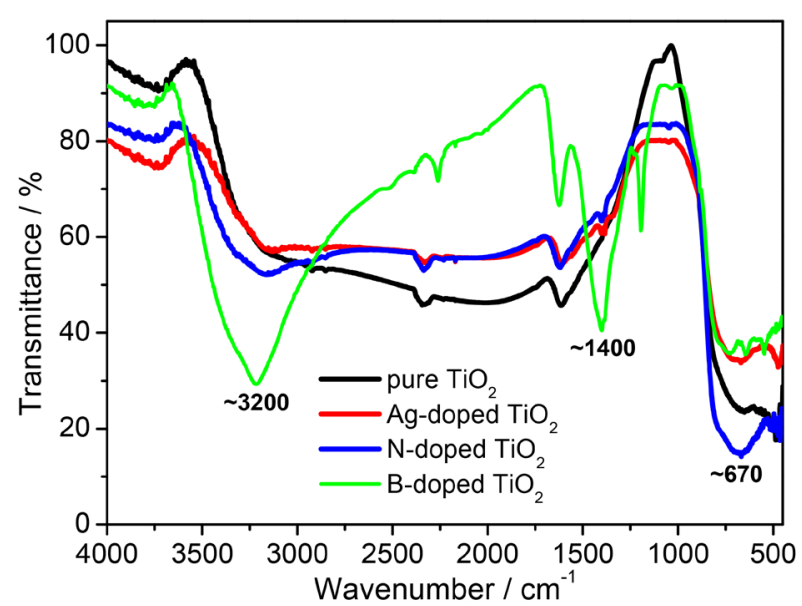

Figure 6. FTIR spectra of pure and doped $\mathrm{TiO}_{2}$.

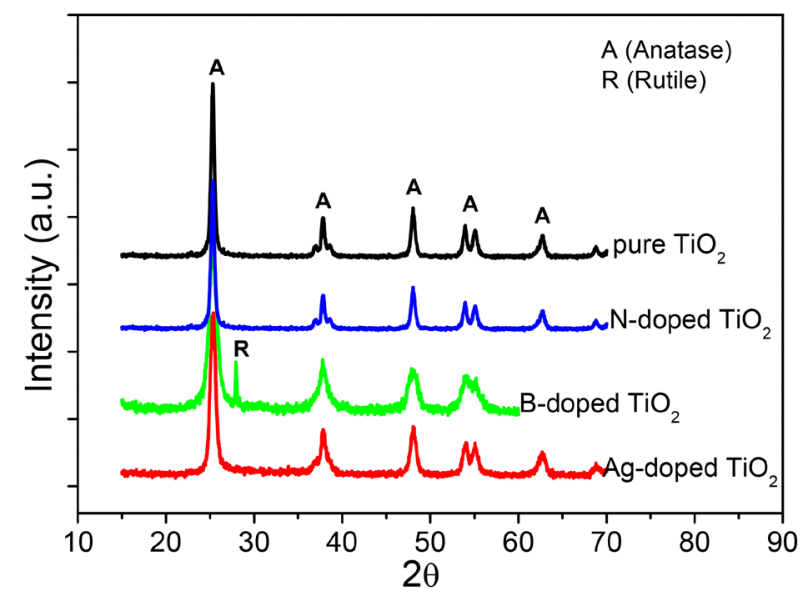

Figure 7. Diffractograms of pure and doped $\mathrm{TiO}_{2}$ calcined at $450{ }^{\circ} \mathrm{C}$.

Surface chemical compositions and oxidation states of pure and $\mathrm{N}$-doped $\mathrm{TiO}_{2}$ were also analyzed by XPS. In the XPS spectra shown in Figure 9, Ti, O, and C peaks are evident. The $\mathrm{C} 1 \mathrm{~s}$ peak located at $284.6 \mathrm{eV}$ results mainly from environmental contamination. For the N-doped catalyst, an N1s peak is observed (see Figure 9, insert), revealing presence of nitrogen in the sample. Table 2 summarizes the surface chemical compositions.

Figures $10 \mathrm{~A}$ and 10B show Ti2p and O1s highresolution spectra obtained for pure and $\mathrm{N}$-doped $\mathrm{TiO}_{2}$. The principal binding energies contributing to the Ti2 $\mathrm{p}_{3 / 2}$ spectra of pure and $\mathrm{N}$-doped $\mathrm{TiO}_{2}$ appear at 458.77 and $457.91 \mathrm{eV}$, respectively. The $5.72 \mathrm{eV}$ distance between $\mathrm{Ti} 2 \mathrm{p}_{3 / 2}$ and $\mathrm{Ti} 2 \mathrm{p}_{1 / 2}$ peaks indicates that titanium is present mostly as $\mathrm{Ti}^{4+},{ }^{4}$ corresponding to relative $\mathrm{TiO}_{2}$ concentrations of 93.44 and $94.12 \%$ in pure and $\mathrm{N}$-doped $\mathrm{TiO}_{2}$, respectively (Table 3). Deconvolution of Ti2p XPS data also revealed presence of $\mathrm{Ti}^{3+}$ in both catalysts. Ti2 $\mathrm{p}_{3 / 2}$ binding energies corresponding to $\mathrm{Ti}^{3+}$ are centered at 457.37 and $456.51 \mathrm{eV}$, respectively, indicating relative $\mathrm{Ti}_{2} \mathrm{O}_{3}{ }^{55}$ concentrations of 6.56 and $5.88 \%$ for pure and $\mathrm{N}$-doped $\mathrm{TiO}_{2}$, respectively.

Figures $10 \mathrm{C}$ and $10 \mathrm{D}$ depict the $\mathrm{O} 1 \mathrm{~s}$ spectra of pure and $\mathrm{N}$-doped $\mathrm{TiO}_{2}$. The $\mathrm{O} 1 \mathrm{~s}$ regions of both catalysts were very similar, showing two peaks (see binding energy values in Table 3) corresponding to Ti-O and surface-adsorbed $\mathrm{O}_{2} / \mathrm{OH}$ groups..$^{55}$

For N-doped $\mathrm{TiO}_{2}$, N1s appeared at $399.0 \mathrm{eV}$ (Figure 11 and Table 3), which may be ascribed to $\mathrm{N}$-doped $\mathrm{TiO}_{2}{ }^{56,57}$ Low intensity precluded reliable assignment of the peak at $399.0 \mathrm{eV}$ (only $0.41 \%$, Table 3), which, however, can be attributed to a number of Ti-N bonding environments, such as formation of O-Ti-N (substitutional N) and TiO-N (interstitial N) structures, ${ }^{56}$ and/or to traces of surfacechemisorbed ammonium ${ }^{58}$ residual from sol-gel synthesis.

BET surface areas $\left(S_{\mathrm{BET}}\right)$, pore volumes $\left(V_{\mathrm{p}}\right)$ and pore diameters $\left(D_{\mathrm{p}}\right)$ are shown in Table 4. Mean $D_{\mathrm{p}}$ lies within the 18.36-6.96 nm range. B-doped $\mathrm{TiO}_{2}$ exhibits larger specific surface areas than the other catalysts, an advantageous trait for photocatalytic performance. These results are in agreement with data from our previous paper ${ }^{12}$ reporting

Table 1. Rietveld refinement parameters of $\mathrm{TiO}_{2}$ samples

\begin{tabular}{|c|c|c|c|c|}
\hline \multirow{2}{*}{$\frac{\text { Parameter / sample }}{\text { Phase }}$} & \multirow{2}{*}{$\frac{\text { Pure } \mathrm{TiO}_{2}}{\text { anatase }}$} & \multirow{2}{*}{$\frac{\mathrm{N} \text {-doped } \mathrm{TiO}_{2}}{\text { anatase }}$} & \multicolumn{2}{|c|}{ Commercial P25-type $\mathrm{TiO}_{2}$} \\
\hline & & & $75 \%$ anatase & $25 \%$ rutile \\
\hline $\mathrm{a}=\mathrm{b} / \AA$ & 3.77972 & 3.78059 & 3.78626 & 4.59446 \\
\hline $\mathrm{c} / \AA$ & 9.48467 & 9.50321 & 9.50680 & 2.95812 \\
\hline$\alpha=\beta=\gamma /$ degree & 90.000 & 90.000 & 90.000 & 90.000 \\
\hline Space group & l41/a $m d z$ & l41/a $m d z$ & l41/a $m d z$ & $p 42 / m n m$ \\
\hline Volume / $\AA^{3}$ & 135.501 & 135.828 & 136.287 & 276.145 \\
\hline Crystallite size / nm & $\begin{array}{l}D_{\text {eq }}=13.3 \\
D_{\text {ax }}=14.4\end{array}$ & $\begin{array}{l}D_{\text {eq }}=17.0 \\
D_{\text {ax }}=20.4\end{array}$ & $\begin{array}{l}D_{\text {eq }}=23.1 \\
D_{\text {ax }}=20.6\end{array}$ & $\begin{array}{l}D_{\text {eq }}=38.8 \\
D_{\text {ax }}=35.3\end{array}$ \\
\hline Refinement parameters & $\begin{aligned} W_{\mathrm{R}} & =9.73 \\
\mathrm{Chi}^{2} & =238 \\
\mathrm{GOF} & =0.36\end{aligned}$ & $\begin{aligned} W_{\mathrm{R}} & =9.31 \\
\mathrm{Chi}^{2} & =222 \\
\mathrm{GOF} & =0.35\end{aligned}$ & & \\
\hline
\end{tabular}

$D_{\text {eq }}$ and $D_{\text {ax }}$ : equatorial and axial diameters of crystallites, respectively. 

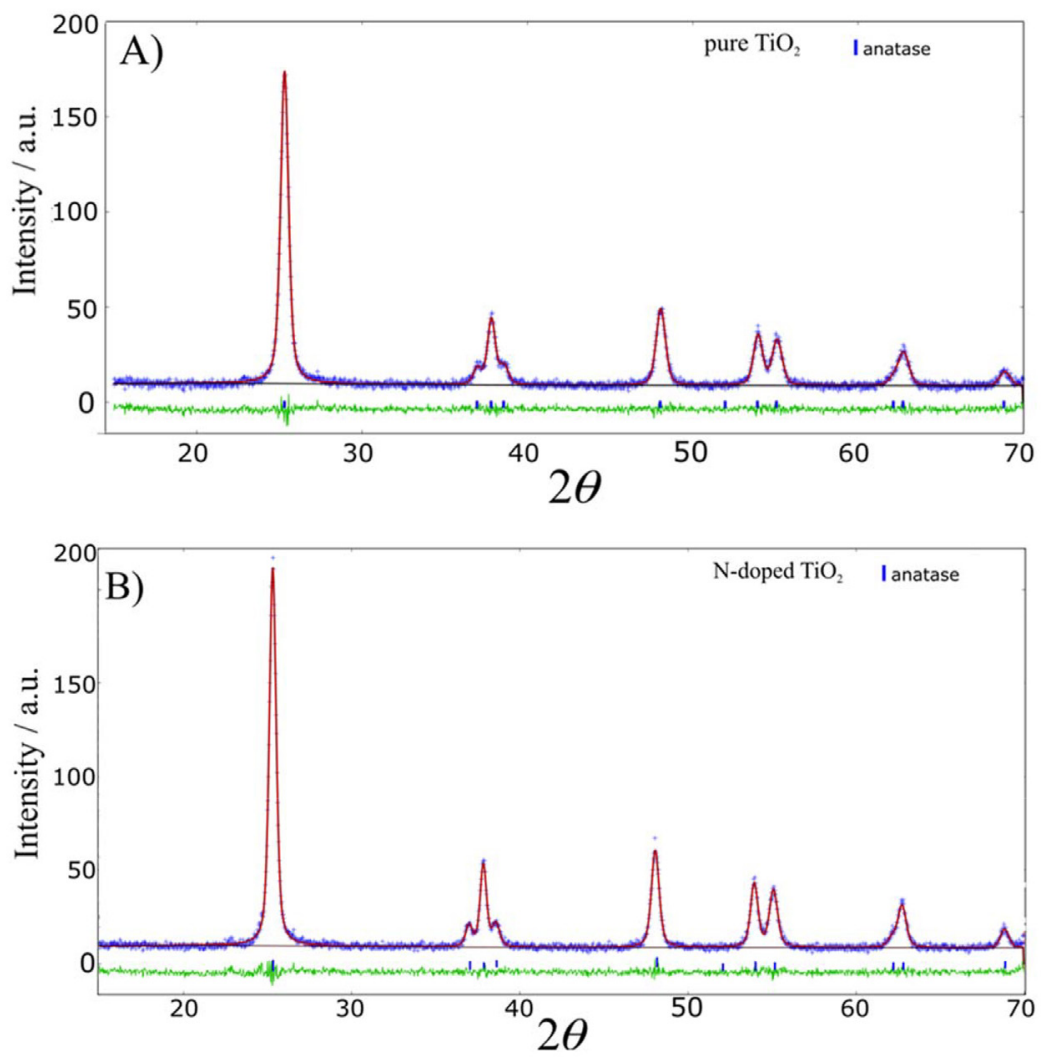

Figure 8. Rietveld refinement plots of (A) pure and (B) $\mathrm{N}$-doped $\mathrm{TiO}_{2}$ prepared using the sol-gel method and calcined at $450{ }^{\circ} \mathrm{C}$. Calculated and observed patterns are shown as red lines and blue crossings, respectively, with residues as green lines. Anatase Bragg peak positions are indicated by blue bars.

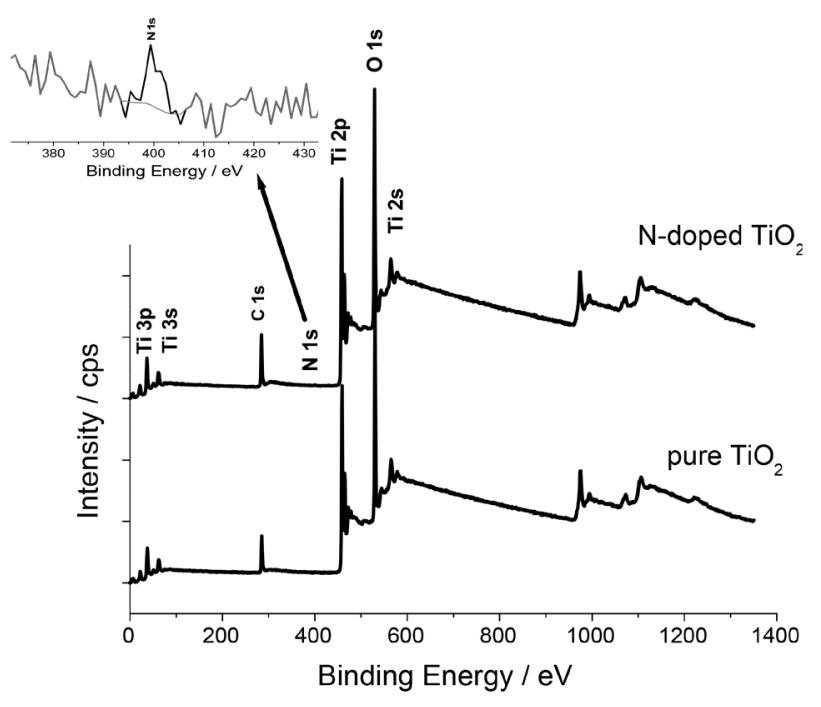

Figure 9. XPS survey of pure and $\mathrm{N}$-doped $\mathrm{TiO}_{2}$.

Table 2. Surface chemical compositions of pure and N-doped $\mathrm{TiO}_{2}$

\begin{tabular}{lcccc}
\hline \multirow{2}{*}{ Catalyst } & \multicolumn{4}{c}{ XPS surface chemical composition /\% } \\
\cline { 2 - 5 } & $\mathrm{N}$ & $\mathrm{O}$ & $\mathrm{Ti}$ & $\mathrm{O} / \mathrm{Ti}$ \\
\hline Pure $\mathrm{TiO}_{2}$ & - & 69.72 & 30.28 & 2.30 \\
N-Doped $\mathrm{TiO}_{2}$ & 0.41 & 70.41 & 29.18 & 2.41 \\
\hline
\end{tabular}

XPS: X-ray photoelectron spectroscopy. that boron presence increases specific surface areas. Pore widths between 2 and $50 \mathrm{~nm}$ correspond to mesopores, and the standard isotherm (Figure 12) is in good agreement with the typical pattern for mesoporous materials (Type IV in the IUPAC classification of physical adsorption isotherms). ${ }^{59}$

For $\mathrm{N}$-doped $\mathrm{TiO}_{2}$, maximum mean pore size distribution, as derived from the desorption branch (BJH model), was found at $18 \mathrm{~nm}$, larger therefore than for B-doped $\mathrm{TiO}_{2}(6.96 \mathrm{~nm})$. Monomodal pore size distribution in the mesoporous region was mainly associated with primary intra-aggregation of nanocrystals of uniform size.$^{60}$

$S_{\text {BET }}$ values are strongly dependent on nitrogen source. The surface area of $\mathrm{N}$-doped $\mathrm{TiO}_{2}\left(68.1 \mathrm{~m}^{2} \mathrm{~g}^{-1}\right)$ was significantly smaller than for the B-doped oxide $\left(126.4 \mathrm{~m}^{2} \mathrm{~g}^{-1}\right)$, indicating that using ammonia in the preparation may result in particle aggregation. These results are in agreement with data obtained by $\mathrm{He}$ et al. ${ }^{60}$

\section{Investigation of photocatalytic efficiency}

The photocatalytic activities of the synthesized oxides were investigated under UV-ABC radiation (maximum emission at $254 \mathrm{~nm}$ ) and with a solar simulator, using MB as an organic model compound at natural $\mathrm{pH}$ ( $\mathrm{pH}$ ca. 5.0). For comparisons, experiments were also performed using $\mathrm{TiO}_{2}$ 

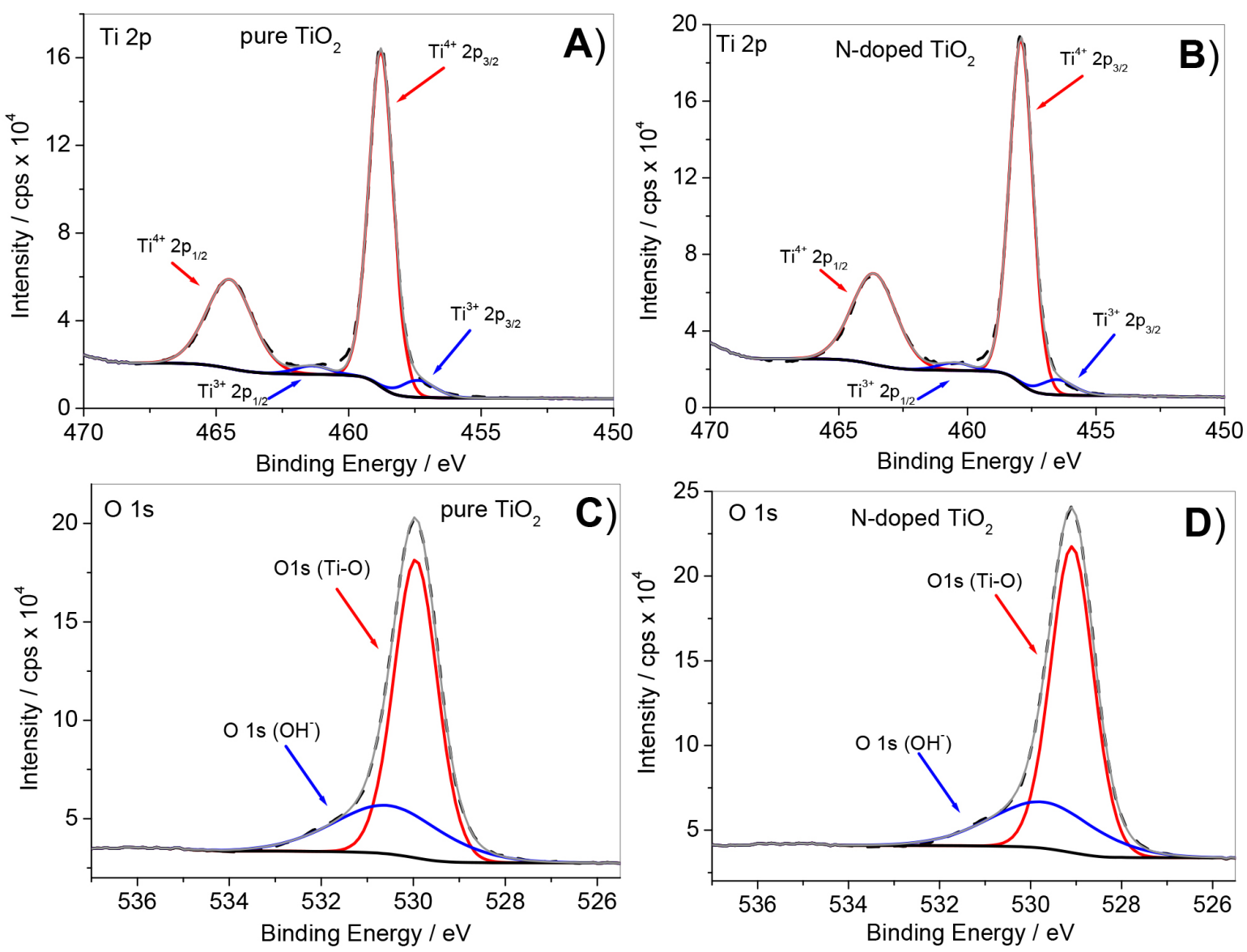

Figure 10. High-resolution XPS Ti2p and O1s spectra of pure (A and C) and $\mathrm{N}$-doped $\mathrm{TiO}_{2}(\mathrm{~B}$ and D).

Table 3. Binding energies (eV) obtained through XPS for pure and $\mathrm{N}$-doped $\mathrm{TiO}_{2}$

\begin{tabular}{lccc}
\hline Region / sample & & $\mathrm{Pure}^{\mathrm{TiO}}$ & \\
\hline \multirow{2}{*}{$\mathrm{C} 1 \mathrm{~s}$} & $\mathrm{C}-\mathrm{C}, \mathrm{C}-\mathrm{H}$ & 284.80 & 284.80 \\
& $\mathrm{C}-\mathrm{OH}, \mathrm{C}-\mathrm{O}-\mathrm{C}$ & 286.30 & 286.30 \\
& $\mathrm{O}-\mathrm{C}=\mathrm{O}$ & 288.80 & 288.80 \\
\hline \multirow{2}{*}{$\mathrm{O} 1 \mathrm{~s}$} & $\mathrm{O}-\mathrm{Ti}$ & 529.95 & 529.09 \\
& $\mathrm{Ti}-\mathrm{OH}$ & 530.55 & 529.74 \\
\hline \multirow{2}{*}{ Ti2 $\mathrm{p}_{3 / 2}$} & $\mathrm{TiO}_{2}$ & 458.77 & 457.91 \\
& $\mathrm{Ti}_{2} \mathrm{O}_{3}$ & 457.37 & 456.51 \\
\multirow{2}{*}{$\mathrm{Ti} 2 \mathrm{p}_{1 / 2}$} & $\mathrm{TiO}_{2}$ & 464.49 & 463.63 \\
& $\mathrm{Ti}_{2} \mathrm{O}_{3}$ & 461.36 & 460.50 \\
\hline N1s & - & - & 399.0 \\
\hline
\end{tabular}

XPS: X-ray photoelectron spectroscopy.

P25 (Evonik) having 75\% anatase and 25\% rutile (Table 1).

The photocatalytic activities of pure and doped $\mathrm{TiO}_{2}$ were first investigated under UV-ABC radiation (120 $\mathrm{mg} \mathrm{L}^{-1}$ of MB and $0.5 \mathrm{~g} \mathrm{~L}^{-1}$ of catalyst) (Figure 13A). Experiments conducted in the absence of catalyst showed that $\mathrm{MB}$ degradation via photolysis was low, relative to

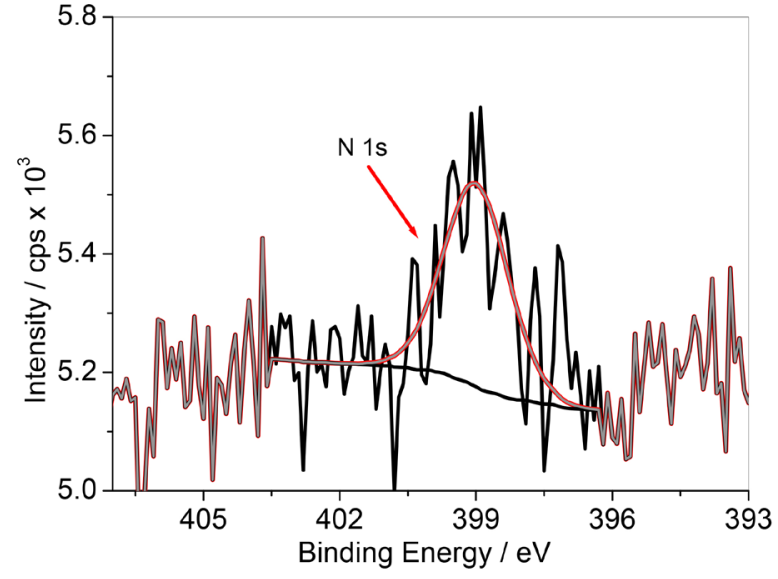

Figure 11. High-resolution N1s XPS spectrum of N-doped $\mathrm{TiO}_{2}$.

Table 4. Surface area data for pure and doped $\mathrm{TiO}_{2}$

\begin{tabular}{lccc}
\hline Catalyst & $S_{\mathrm{BET}} /\left(\mathrm{m}^{2} \mathrm{~g}^{-1}\right)$ & $V_{\mathrm{p}}^{\mathrm{a}} /\left(\mathrm{cm}^{3} \mathrm{~g}^{-1}\right)$ & $D_{\mathrm{p}} / \mathrm{nm}$ \\
\hline Pure $\mathrm{TiO}_{2}$ & $69.5 \pm 0.2$ & 0.197 & 11.35 \\
N-doped $\mathrm{TiO}_{2}$ & $68.1 \pm 0.14$ & 0.313 & 18.36 \\
B-doped $\mathrm{TiO}_{2}$ & $126.4 \pm 0.17$ & 0.220 & 6.96 \\
Ag-doped $\mathrm{TiO}_{2}$ & $67.4 \pm 0.16$ & 0.227 & 13.47
\end{tabular}

abtained from the volume of $\mathrm{N}_{2}$ adsorbed at $P / P_{0}=0.98$. 

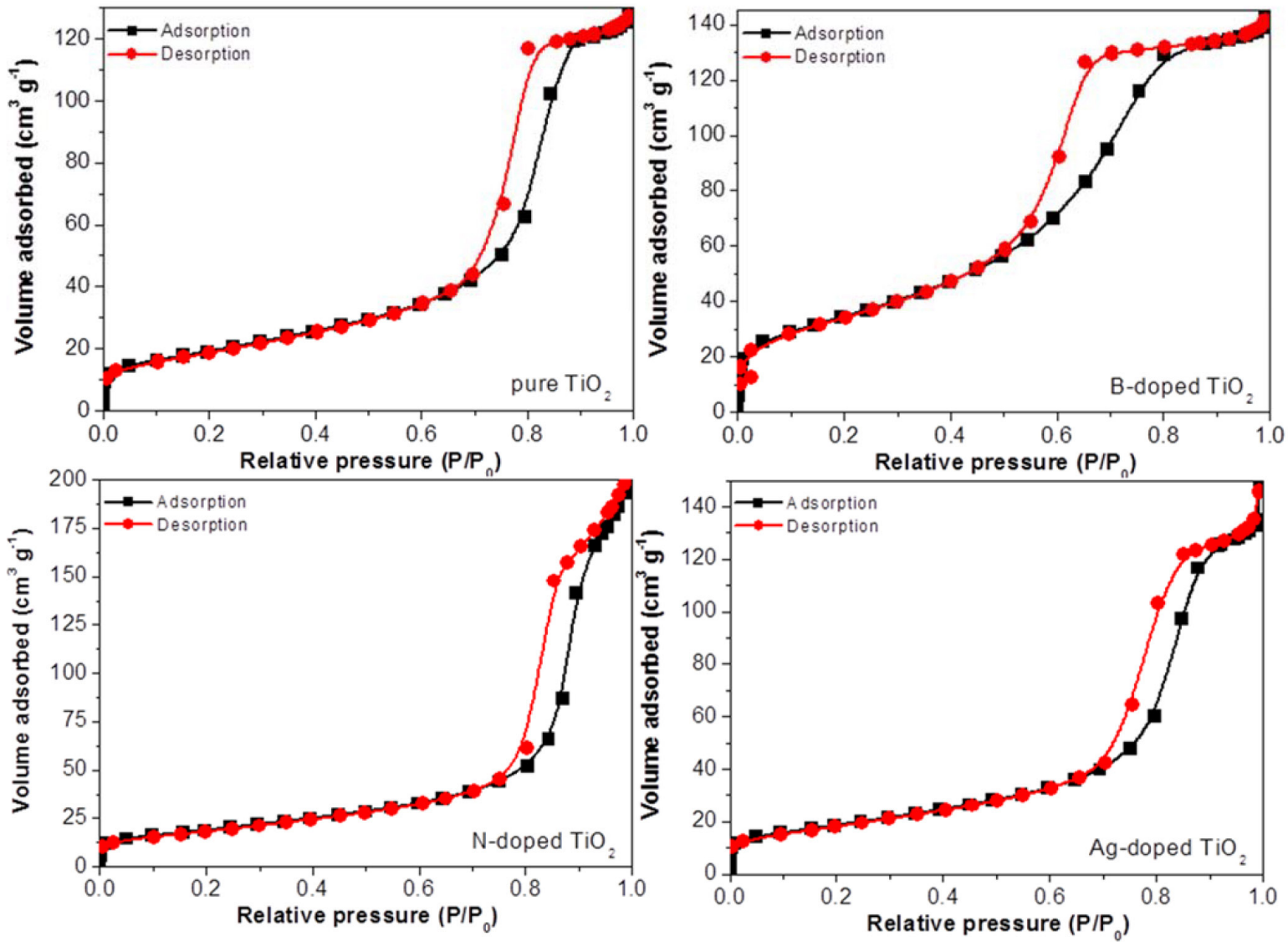

Figure 12. Nitrogen adsorption-desorption isotherms for pure and doped $\mathrm{TiO}_{2}$.

the corresponding photocatalysis, resulting in ca. $37 \%$ decomposition with 180 min UV-ABC irradiation (Table 5). In the presence of $\mathrm{B}$ - or Ag-doped $\mathrm{TiO}_{2}, \mathrm{MB}$ decomposition decreased, compared with pure $\mathrm{TiO}_{2}$. MB removal using pure $\mathrm{TiO}_{2}$ as a photocatalyst reached $89 \%$ at $180 \mathrm{~min}$ of irradiation, while only 52 and $73 \%$ of MB were decomposed with Ag- and B-doped oxide, respectively, possibly owing to excess dopant, resulting in poorer photocatalytic activity probably consequent to the appearance of new sites for electron-hole recombination. Working with phenol degradation under UV radiation, Zaleska et $a l . .^{34}$ reported lower photocatalytic activity of B-doped $\mathrm{TiO}_{2}$, compared with pure $\mathrm{TiO}_{2}$ synthesized by the sol-gel method. A higher amount of boron dopant resulted in the appearance of a sassolite phase $\left(\mathrm{H}_{3} \mathrm{BO}_{3}\right)$, which decreased the photocatalytic activity, depending on the type of organic compound tested. ${ }^{61}$

Increased adsorption capacity of $\mathrm{TiO}_{2}$ with $\mathrm{Ag}$-doping has been reported ${ }^{62,63}$ but this effect has not been consistently observed ${ }^{64,65}$ For the photocatalysts synthesized in this present study, a reduction in degradation rate was observed. According to Ramos et al. ${ }^{14}$ this possibly occurs because maximum saturation is reached on the semiconductor surface and excess silver occupies active sites in the catalyst, decreasing catalytic activity by lowering the incidence of radiation on $\mathrm{TiO}_{2}$ particles and decreasing the number of active sites for substrate adsorption.

Lin et al ${ }^{66}$ prepared $\mathrm{TiO}_{2} / \mathrm{Ag}$ composites and evaluated the effect that operational $\mathrm{pH}$ of the synthesis process had on the zeta potentials of $\mathrm{TiO}_{2}$ and $\mathrm{Ag}$ carrier. Isoelectric points $(\mathrm{pH}$ values at which the compound has a zero net charge) of 4.0 and 6.8 were found for $\mathrm{Ag}$ and $\mathrm{TiO}_{2}$, respectively. Morphological surface analysis via SEM of $\mathrm{TiO}_{2} / \mathrm{Ag}$ thus prepared revealed that, at $\mathrm{pH} 3.0, \mathrm{TiO}_{2}$ and $\mathrm{Ag}$ had the same surface electrical charges, repelling each other and precluding $\mathrm{TiO}_{2}$ nanoparticles from easily attaching to the Ag surface, although not preventing mutual aggregation of $\mathrm{TiO}_{2}$ nanoparticles. By maintaining the synthesis solution at $\mathrm{pH}$ 5.8, $\mathrm{TiO}_{2}$ and $\mathrm{Ag}$ particles exhibited opposite surface charges with maximum difference, resulting in high $\mathrm{TiO}_{2}$ dispersibility and optimal combination between $\mathrm{TiO}_{2}$ and $\mathrm{Ag}$, with best performance in photodegrading acetone, the model compound employed. Conversely, $\mathrm{TiO}_{2} / \mathrm{Ag}$ prepared at $\mathrm{pH} 3.0$ proved the least efficient. In the present study, synthesis was carried out in acidic medium and $\mathrm{TiO}_{2}$ and $\mathrm{Ag}$ exhibited the same electrical properties, causing $\mathrm{TiO}_{2}$ to aggregate or disperse only partially on the $\mathrm{Ag}$ surface, which explains the low rate of MB removal observed. 

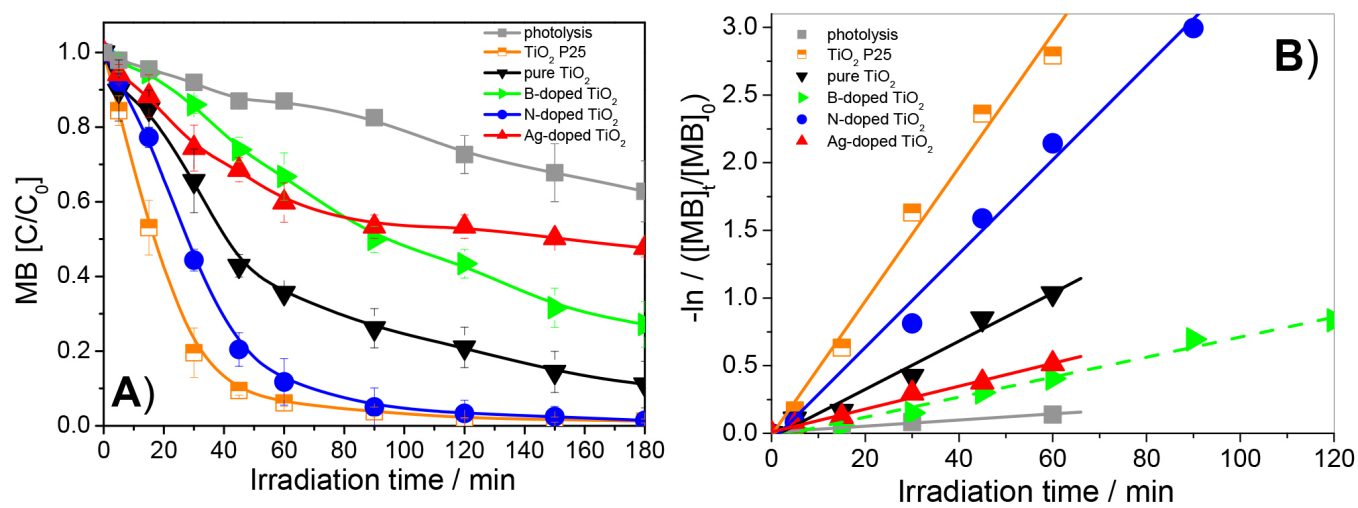

Figure 13. (A) Methylene blue degradation curves: $[\mathrm{MB}]_{0}=120 \mathrm{mg} \mathrm{L}^{-1}$; [catalyst $]=0.5 \mathrm{~g} \mathrm{~L}^{-1}$ under UV-ABC radiation; (B) pseudo-first-order kinetic constant calculation.

In the present study, by contrast, $\mathrm{N}$-doping significantly improved $\mathrm{TiO}_{2}$ performance $(95 \%$ degradation for $\mathrm{N}$-doped $\mathrm{TiO}_{2}$ vs. $74 \%$ for pure $\mathrm{TiO}_{2}$ with 90 min irradiation). Compared with $\mathrm{TiO}_{2} \mathrm{P} 25$, the $\mathrm{N}$-doped oxide proved efficient, completely removing MB with 180 min UV-ABC irradiation $\left(\lambda_{\max }=254 \mathrm{~nm}\right)$. The high activity of $\mathrm{TiO}_{2} \mathrm{P} 25$ results from the optimization of parameters such as phase composition, crystallite size, and surface area. ${ }^{67}$

Non-metal dopants have been described as more efficient than most metal ions, owing to less pronounced formation of recombination centers. ${ }^{10}$ Nitrogen in N-doped $\mathrm{TiO}_{2}$ leads to formation of $\mathrm{Ti}^{3+}$ species, which can trap photogenerated electrons in the conduction band and prevent recombination of electron-hole pairs. ${ }^{68}$ Therefore, formation of $\mathrm{Ti}^{3+}$ species enhances photocatalytic activity, which is evident from XPS spectra (see Figure 10B). Crystallite size also has a pronounced effect: the enhanced photocatalytic activity of $\mathrm{N}$-doped $\mathrm{TiO}_{2}$ can be attributed to its smaller crystal size (seen with Rietveld refinement), which accelerates surface charge transfer, decreasing the likelihood of recombination of photoinduced electron-hole pairs. ${ }^{36}$

To quantify differences in degradation rates, $\mathrm{MB}$ oxidation data were employed to calculate $k_{\text {ap }}$, the pseudofirst-order kinetic constant (Table 5), from the slope of the regression line representing $-\ln \left([\mathrm{MB}]_{\mathrm{r}} /[\mathrm{MB}]_{0}\right)$ vs. time (Figure 13B), where $[\mathrm{MB}]_{0}$ and $[\mathrm{MB}]_{\mathrm{t}}$ are the initial concentration and the concentration after $t$ minutes of irradiation, respectively. The magnitude of $k_{\mathrm{ap}}$ follows the order $\mathrm{TiO}_{2} \mathrm{P} 25>\mathrm{N}$-doped $\mathrm{TiO}_{2}>$ pure $\mathrm{TiO}_{2}>$ Ag-doped $\mathrm{TiO}_{2}>$ B-doped $\mathrm{TiO}_{2}$. N-doped $\mathrm{TiO}_{2}$ proved roughly 2.2 times more effective than pure $\mathrm{TiO}_{2}$ in degrading MB. The photocatalytic efficiency of synthesized $\mathrm{N}$-doped $\mathrm{TiO}_{2}$ was quite similar to that of $\mathrm{TiO}_{2} \mathrm{P} 25$.

To investigate photocatalytic activity under visiblelight irradiation, experiments were performed in a solar simulator using $40 \mathrm{mg} \mathrm{L}^{-1}$ of $\mathrm{MB}$ and $0.4 \mathrm{~g} \mathrm{~L}^{-1}$ of catalyst
Table 5. Methylene blue degradation rates and respective pseudo-firstorder kinetic constants $\left(k_{\mathrm{ap}}\right)$ for experiments conducted under UV-ABC radiation

\begin{tabular}{lccc}
\hline Photocatalyst & Degradation $/ \%$ & $k_{\text {ap }} / \mathrm{min}^{-1}$ & $\mathrm{R}$ \\
\hline Photolysis & 37 & $0.23 \times 10^{-2}$ & 0.996 \\
$\mathrm{TiO}_{2} \mathrm{P} 25$ & 99 & $4.95 \times 10^{-2}$ & 0.994 \\
$\mathrm{Pure}_{\mathrm{TiO}}$ & 89 & $1.78 \times 10^{-2}$ & 0.988 \\
B-doped $\mathrm{TiO}_{2}$ & 73 & $0.74 \times 10^{-2}$ & 0.994 \\
Ag-doped $\mathrm{TiO}_{2}$ & 52 & $0.85 \times 10^{-2}$ & 0.996 \\
N-doped $\mathrm{TiO}_{2}$ & 98 & $3.47 \times 10^{-2}$ & 0.996 \\
\hline
\end{tabular}

(Figure 14 and Table 6). $\mathrm{N}$-doped $\mathrm{TiO}_{2}$ exhibited the highest photocatalytic activity (88\% of MB removal with 180 min irradiation), with a kinetic constant (calculated from Figure 14B data, using $\ln \left(C / C_{0}\right) v s$. time fitting) of $1.12 \times 10^{-2} \mathrm{~min}^{-1}$ (Table 6), roughly 3.6 times that for pure $\mathrm{TiO}_{2}\left(0.31 \times 10^{-2} \mathrm{~min}^{-1}\right)$ and similar to the kinetic constant for $\mathrm{TiO}_{2} \mathrm{P} 25\left(1.61 \times 10^{-2} \mathrm{~min}^{-1}\right)$.

Incorporation of non-metals to the catalyst creates heteroatomic surface structures, modifying the properties and activity of $\mathrm{TiO}_{2}$ under visible light. ${ }^{69} \mathrm{~N}$-doping accounts for the red shift observed at the light absorption edge, narrowing the bandgap. ${ }^{36}$ For comparison, simulated UV-Vis irradiation for $180 \mathrm{~min}$ in the absence of photocatalyst failed to degrade MB. Pure and Ag-doped $\mathrm{TiO}_{2}$ led to lower MB degradation, of roughly 60 and $42 \%$, respectively, with $180 \mathrm{~min}$ treatment, while for the B-doped oxide this rate reached ca. $65 \%$. Over the same period, ca. 92\% degradation was achieved with $\mathrm{TiO}_{2} \mathrm{P} 25$.

To investigate catalyst efficiency under visible radiation alone, a $400 \mathrm{~nm}$ longpass filter was employed. As shown in Figure 15, negligible (5\%) MB degradation was observed for photolysis $(\lambda>400 \mathrm{~nm})$ conducted in the absence of catalysts, while $\mathrm{N}$-doped $\mathrm{TiO}_{2}$ proved more efficient than $\mathrm{TiO}_{2} \mathrm{P} 25$. The high activity of $\mathrm{N}$-doped $\mathrm{TiO}_{2}$ under visible-light irradiation has been attributed to nitrogen 

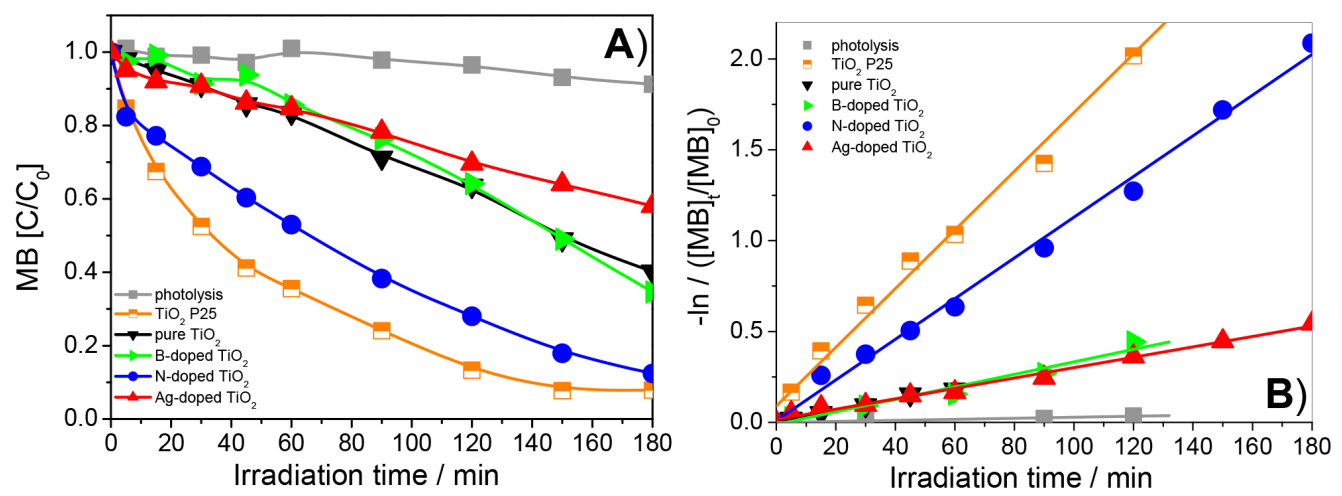

Figure 14. (A) Methylene blue (MB) degradation in a solar simulator device: $[\mathrm{MB}]_{0}=40 \mathrm{mg} \mathrm{L}{ }^{-1}$; [catalyst $=0.5 \mathrm{~g} \mathrm{~L}$ L $^{-1}$; (B) pseudo-first-order kinetic constant calculation.

Table 6. Methylene blue removal rates and pseudo-first-order kinetic constants $\left(k_{\text {ap }}\right)$ obtained in a solar simulator device

\begin{tabular}{lccc}
\hline Photocatalyst & Degradation $/ \%$ & $k_{\text {ap }} / \mathrm{min}^{-1}$ & $\mathrm{R}$ \\
\hline None (photolysis) & 9 & $0.03 \times 10^{-2}$ & 0.990 \\
$\mathrm{TiO}_{2} \mathrm{P} 25$ & 92 & $1.61 \times 10^{-2}$ & 0.997 \\
$\mathrm{Pure}_{\mathrm{TiO}}$ & 60 & $0.31 \times 10^{-2}$ & 0.996 \\
$\mathrm{~B}$-doped $\mathrm{TiO}_{2}$ & 65 & $0.34 \times 10^{-2}$ & 0.983 \\
Ag-doped $\mathrm{TiO}_{2}$ & 42 & $0.29 \times 10^{-2}$ & 0.995 \\
N-doped $\mathrm{TiO}_{2}$ & 88 & $1.12 \times 10^{-2}$ & 0.997 \\
\hline
\end{tabular}

species responsible for the red shift detected at the light absorption edge. ${ }^{36}$ Hurum et al. ${ }^{70}$ reported that presence of a rutile phase in $\mathrm{TiO}_{2} \mathrm{P} 25$ extends photoactivity into the visible range, which explains why the photocatalytic activity observed under visible light $(\lambda>400 \mathrm{~nm})$ was low.

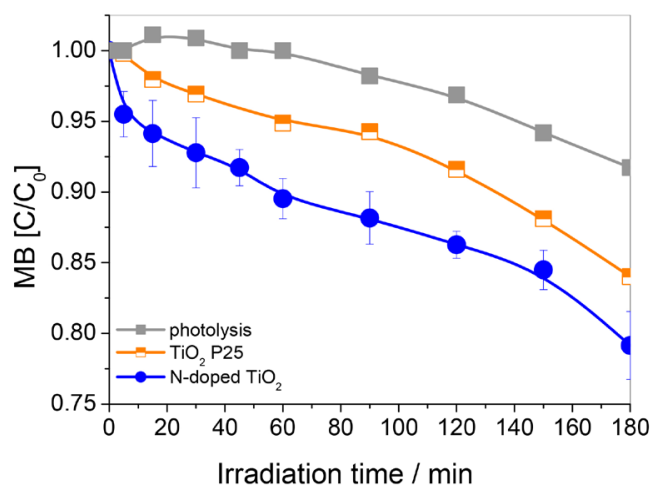

Figure 15. Methylene blue (MB) degradation by $\mathrm{TiO}_{2} \mathrm{P} 25$ and $\mathrm{N}$-doped $\mathrm{TiO}_{2}$ in a solar simulator device using a longpass filter (> $\left.400 \mathrm{~nm}\right)$ : $[\mathrm{MB}]_{0}=40 \mathrm{mg} \mathrm{L}^{-1}$; [catalyst $]=0.5 \mathrm{~g} \mathrm{~L}^{-1}$.

\section{Conclusions}

In this investigation of novel photocatalysts synthesized using the sol-gel method, TGA and FTIR measurements showed surface water absorption to be most pronounced for
B-doped $\mathrm{TiO}_{2}$, without major changes to bandgap energy values. $E_{\text {gap }}$ of Ag-doped $\mathrm{TiO}_{2}$ was slightly lower than for the other catalysts. Rietveld refinement data revealed the powders to have a $100 \%$ anatase crystalline structure. XPS data indicated the presence of $\mathrm{Ti}^{3+}$ in pure and $\mathrm{N}$-doped $\mathrm{TiO}_{2}$.

Degradation efficiency was evaluated by MB removal and pseudo-first-order kinetic parameters in experiments carried out under UV-ABC and solar light radiation. MB photodegradation results showed that the photocatalytic efficiency of $\mathrm{TiO}_{2}$ was substantially enhanced by $\mathrm{N}$-doping, for both radiation sources. Despite its ability to absorb radiation in the visible region, $\mathrm{Ag}$-doped $\mathrm{TiO}_{2}$ exhibited lower photocatalytic performance than the other synthesized catalysts.

Under visible radiation, $\mathrm{N}$-doped $\mathrm{TiO}_{2}$ showed higher photocatalytic efficiency than $\mathrm{TiO}_{2} \mathrm{P} 25$. The superior activity of $\mathrm{N}$-doped $\mathrm{TiO}_{2}$ relative to pure $\mathrm{TiO}_{2}$ can be attributed to synergic effects of nitrogen species, small crystallite size, and the consequent decrease in photoinduced electron-hole pair recombination.

The results showed synthesis by the sol-gel method to be a simple method to produce efficient photocatalysts for removal of organic compounds. In addition, the efficiency demonstrated by these catalysts under sunlight irradiation allows lowering the cost of photocatalytic processes.

\section{Acknowledgments}

The authors wish to thank the Brazilian funding agencies CNPq (projects 486342/2013-1 and 311798/2014-4), CAPES (for the grants awarded to P. C. S. B. and R. P. C.), and FUNDECT (project 23/200.247/2014). Thanks are also extended to the Brazilian National Nanotechnology Laboratory (LNNano) for the XPS experimental facilities (proposal XPS-20373). 


\section{References}

1. Santiago-Morales, J.; Agüera, A.; Gómez, M. M.; FernándezAlba, A. R.; Giménez, J.; Esplugas, S.; Rosal, R.; Appl. Catal., B 2013, 129, 13 .

2. Malato, S.; Fernández-Ibáñez, P.; Maldonado, M. I.; Blanco, J.; Gernjak, W.; Catal. Today 2009, 147, 1.

3. Cavalcante, R. P.; Sandim, L. R.; Bogo, D.; Barbosa, A. M. J.; Osugi, M. E.; Blanco, M.; Oliveira, S. C.; Matos, M. F. C.; Machulek Jr., A.; Ferreira, V. S.; Environ. Sci. Pollut. Res. 2013, 20,2352.

4. Klavarioti, M.; Mantzavinos, D.; Kassinos, D.; Environ. Int. 2009, 35, 402.

5. Méndez-Arriaga, F.; Esplugas, S.; Giménez, J.; Water Res. 2010 , 44, 589.

6. Andreozzi, R.; Caprio, V.; Insola, A.; Marotta, R.; Catal. Today 1999, 53, 51.

7. Rauf, M. A.; Ashraf, S. S.; Chem. Eng. J. 2009, 151, 10.

8. Banerjee, S.; Dionysiou, D. D.; Pillai, S. C.; Appl. Catal., B 2015, 176-177, 396.

9. Cavalcante, R. P.; Dantas, R. F.; Bayarri, B.; Gonzalez, O.; Giménez, J.; Esplugas, S.; Machulek Jr., A.; Appl. Catal., B 2016, 194, 111.

10. Etacheri, V.; Valentin, C. D.; Schneider, J.; Bahnemann, D.; Pillai, S. C.; J. Photochem. Photobiol., C 2015, 25, 1.

11. Ahmed, S.; Rasul, M. G.; Martens, W. N.; Brown, R.; Hashib, M. A.; Desalination 2010, 261, 3.

12. Cavalcante, R. P.; Dantas, R. F.; Bayarri, B.; González, O.; Giménez, J.; Esplugas, S.; Machulek Jr., A.; Catal. Today 2015 , 252, 27.

13. Cavalcante, R. P.; Dantas, R. F.; Bayarri, B.; González, O.; Wender, H.; Giménez, J.; Esplugas, S.; Machulek Jr., A.; Appl. Catal., B 2015, 176-177, 173.

14. Ramos, D. D.; Bezerra, P. C. S.; Quina, F. H.; Dantas, R. F.; Casagrande, G. A.; Oliveira, S. C.; Oliveira, M. R. S.; Oliveira, L. C. S.; Ferreira, V. S.; Oliveira, S. L.; Machulek Jr., A.; Environ. Sci. Pollut. Res. 2015, 22, 774.

15. Castro, D. C.; Cavalcante, R. P.; Jorge, J.; Martines, M. A. U.; Oliveira, L. C. S.; Casagrande, G. A.; Machulek Jr., A.; J. Braz. Chem. Soc. 2016, 27, 303.

16. Sarkar, S.; Chakraborty, S.; Bhattacharjee, C.; Ecotoxicol. Environ. Saf. 2015, 121, 263.

17. The, M.; Mohamed, A. R.; J. Alloys Compd. 2011, 509, 1648.

18. Miranda-García, N.; Maldonado, M. I.; Coronado, J. M.; Malato, S.; Catal. Today 2010, 151, 107.

19. Malato, S.; Maldonado, M. I.; Fernández-Ibáñez, P.; Oller, I.; Polo, I.; Sánchez-Moreno, R.; Mater. Sci. Semicond. Process. 2016, 42, 15.

20. http://www.agenciabrasilia.df.gov.br/2013/02/20/membranada-cobertura-do-estadio-foto/, accessed on September 28, 2016.
21. Doorslaer, X. V.; Dewulf, J.; Maerschalk, J. D.; Langenhove, H. V.; Demeestere, K.; Chem. Eng. J. 2015, 261, 9.

22. Malato, S.; Blanco, J.; Vidal, A.; Alarcón, D.; Maldonado, M. I.; Cáceres, J.; Gernjak, W.; Sol. Energy 2003, 75, 329.

23. Devi, L. G.; Kavitha, R.; Appl. Catal., B 2013, 140-141, 559.

24. Henderson, M. A.; Surf. Sci. Rep. 2011, 66, 185.

25. Diebold, U.; Surf. Sci. Rep. 2003, 48, 53.

26. Linsebigler, A. L.; Lu, G.; Yates, J. T.; Chem. Rev. 1995, 95 , 735.

27. Li, H.; Hao, Y.; Lu, H.; Liang, L.; Wang, Y.; Qiu, J.; Shi, X.; Wang, Y.; Yao, J.; Appl. Surf. Sci. 2015, 344, 112.

28. Chen, Y.; Liu, K.; Powder Technol. 2016, 303, 176.

29. Zhang, L.; Tan, P. Y.; Lim, C. K.; Guo, X.; Tse, M. S.; Tan, O. K.; Chang, V. W. C.; J. Environ. Chem. Eng. 2016, 4, 357.

30. Nishijima, K.; Kamai, T.; Murakami, N.; Tsubota, T.; Ohno, T.; Int. J. Photoenergy 2008, 2008, 1.

31. Ivanov, S.; Barylyak, A.; Besaha, K.; Bund, A.; Bobitski, Y.; Wojnarowska-Nowak, R.; Yaremchuk, I.; Kus-Li kiewicz, M.; Nanoscale Res. Lett. 2016, 11, 140.

32. Wang, W.-K.; Chen, J.-J.; Gao, M.; Huang, Y.-X.; Zhang, X.; Yu, H.-Q.; Appl. Catal., B 2016, 195, 69.

33. Liang, L.; Yulin, Y.; Xinrong, L.; Ruiqing, F.; Yan, S.; Shuo, L.; Lingyun, Z.; Xiao, F.; Pengxiao, T.; Rui, X.; Wenzhi, Z.; Yazhen, W.; Liqun, M.; Appl. Surf. Sci. 2013, 265, 36.

34. Zaleska, A.; Sobczak, J. W.; Grabowska, E.; Hupka, J.; Appl. Catal., B 2008, 78, 92.

35. Quiñones, D. H.; Rey, A.; Álvarez, P. M.; Beltrán, F. J.; Puma, G. L.; Appl. Catal., B 2015, 178, 74.

36. Elghniji, K.; Ksibi, M.; Elaloui, E.; J. Ind. Eng. Chem. 2012, 18, 178 .

37. Fujiwara, K.; Deligiannakis, Y.; Skoutelis, C. G.; Pratsinis, S. E.; Appl. Catal., B 2014, 154-155, 9.

38. Giannakas, A. E.; Seristatidou, E.; Deligiannakis, Y.; Konstantinou, I.; Appl. Catal., B 2013, 132-133, 460.

39. Jian-xiao, L. V.; Ying, C.; Guo-hong, X.; Ling-yun, Z.; Su-fen, W.; J. Water Reuse Desalin. 2011, 1, 45.

40. Mohabansi, N. P.; Patil, V. B.; Yenkie, N.; Rasayan J. Chem. 2011, 4, 814.

41. Abramoff, M. D.; Magalhaes, P. J.; Ram, S. J.; Biophotonics Int. 2004, 11, 36.

42. Rietveld, H. M.; J. Appl. Crystallogr. 1969, 2, 65.

43. Toby, B. H.; Von Dreele, R. B.; J. Appl. Crystallogr. 2013, 46, 544.

44. Shen, J.; Li, Y.; He, J.-H.; Dyes Pigm. 2016, 127, 187.

45. Malengreaux, C. M.; Douven, S.; Poelman, D.; Heinrichs, B.; Bartlett, J. R.; J. Sol-Gel Sci. Technol. 2014, 71, 557.

46. Zoschke, K.; Börnick, H.; Worch, E.; Water Res. 2014, 52, 131.

47. Braun, A. M.; Maurette, M. T.; Oliveiros, E.; Photochemical Technology; John Wiley: Chichester, 1991.

48. Moon, O. M.; Kang, B.-C.; Lee, S.-B.; Boo, J.-H.; Thin Solid Films 2004, 464-465, 164. 
49. Giannakas, A. E.; Antonopoulou, M.; Daikopoulos, C.; Deligiannakis, Y.; Konstantinou, I.; Appl. Catal., B 2016, 184, 44.

50. Chen, X.; Kuo, D.-H.; Lu, D.; Chem. Eng. J. 2016, 295, 192.

51. Lei, X. F.; Xue, X. X.; Yang, H.; Appl. Surf. Sci. 2014, 321, 396.

52. Simsek, E. B.; Appl. Catal., B 2017, 200, 309.

53. Silverstein, R. M.; Bassler, G. C.; Morrill, T. C.; Identificação Espectrofotométrica de Compostos Orgânicos; Editora Guanabara: Rio de Janeiro, Brazil, 1979.

54. Wagner, C. D.; Naumkin, A. V.; Kraut-Vass, A.; Allison, J. W.; Powell, C. J.; Rumble Jr., J. R.; NIST Standard Reference Database 20, version 3.4 (web version) (http:/srdata.nist.gov/ $\mathrm{xps} /), 2003$.

55. Biesinger, M. C.; Lau, L. W. M.; Gerson, A.; Smart, R. St. C.; Appl. Surf. Sci. 2010, 257, 887.

56. Chen, X.; Lou, Y.; Samia, A.; Burda, C.; Gole, J. L.; Adv. Funct. Mater. 2005, 15, 41.

57. Kuznetsov, M. V.; Zhuravlev, Ju. F.; Zhilyaev, V. A.; Gubanov, V. A.; J. Electron Spectrosc. Relat. Phenom. 1992, 58, 1.

58. Arienzo, M. D.; Scotti, R.; Wahba, L.; Battocchio, C.; Bemporad, E.; Nale, A.; Morazzoni, F.; Appl. Catal., B 2009, 93, 149.

59. Sing, K. S. W.; Pure Appl. Chem. 1985, 57, 603.

60. He, F.; Ma, F.; Li, T.; Li, G.; Chin. J. Catal. 2013, 34, 2263.

61. Stengl, V.; Housková, V.; Bakardjieva, S.; Murafa, N; ACS Appl. Mater. Interfaces 2010, 2, 575.
62. Tahir, K.; Ahmad, A.; Li, B.; Nazir, S.; Khan, A. U.; Nasir, T.; Khan, Z. U. H.; Naz, R.; Raza, M.; J. Photochem. Photobiol., B 2016, 162, 189.

63. Kumar, R.; Rashid, J.; Barakat, M. A.; Colloid Interface Sci. Commun. 2015, $5,1$.

64. Tryba, B.; Piszcz, M.; Morawski, A.W.; Open Mater. Sci. J. 2010, 4,5 .

65. Tran, H.; Scott, J.; Chiang, K.; Amal, R.; J. Photochem. Photobiol., A 2006, 183, 41.

66. Lin, Y.-C.; Bai, H.; Lin, C.-H.; Wu, J.-F.; Aerosol Air Qual. Res. 2013, 13, 1512.

67. Gumy, D.; Rincon, A. G.; Hajdu, R.; Pulgarin, C.; Sol. Energy 2006, 80, 1376.

68. Bhosale, R. R.; Pujari, S. R.; Muley, G. G.; Patil, S. H.; Patil, K. R.; Shaikh, M. F.; Gambhire, A. B.; Sol. Energy 2014, 103, 473.

69. Ola, O.; Maroto-Valer, M. M.; J. Photochem. Photobiol., C 2015, 24, 16.

70. Hurum, D. C.; Agrios, A. G.; Gray, K. A.; J. Phys. Chem. B 2003, 107, 4545 .

Submitted: September 29, 2016

Published online: February 24, 2017 